\title{
UTILIZAÇÃO DE MULTIMÉTODOS \\ DE CARACTERIZAÇÃO E ANÁLISE \\ DA PAISAGEM E DOS ESPAÇOS LIVRES \\ INTRAURBANOS DE SANTA MARIA-RS
}

\author{
METHODOLOGY FOR CHARACTERIZING AND \\ ANALYZING PUBLIC INTRAURBAN SPACES IN SANTA MARIA-RS
}

Luis Guilherme Aita Pippi*

Letícia de Castro Gabriel**

Renata Michelon Cocco***

Letícia de Fátima Durlo Coutinho****

Henrique Schwingel ${ }^{* * * * *}$

Marcos Guterres Giovelli******

* Arquiteto e urbanista, mestre em Arquitetura e Urbanismo pela Universidade Federal de Santa Catarina (UFSC). PhD CAPES/Fulbright, Dep. Landscape Architecture, College of Design, NC State University (EUA). Doutor em Arquitetura e Urbanismo (Paisagem e Ambiente) pela Faculdade de Arquitetura e Urbanismo da Universidade de São Paulo (FAUUSP). Professor adjunto do Curso de Arquitetura e Urbanismo da Universidade Federal de Santa Maria (UFSM) e coordenador do grupo de pesquisa nacional Quapá-SEL II, Núcleo Santa Maria. Rua Felix Mainardi, 65, 97110 633, Parque Fiori D'itália, Camobi, Santa Maria, RS, Brasil.

guiamy@hotmail.com

** Arquiteta e urbanista pela Universidade Federal de Santa Maria (UFSM), mestre em Urbanismo, História e Arquitetura da Cidade pela Universidade Federal de Santa Catarina (UFSC). Professora do Curso de Arquitetura e Urbanismo da UFSM, Campus Cachoeira do Sul. Avenida Presidente Vargas, 1.958, 96506-302, Santo Antônio, Cachoeira do Sul, RS, Brasil.

leticia.gabriel@ufsm.br

*** Aluna do Curso de Arquitetura e Urbanismo da Universidade Federal de Santa Maria (UFSM). Rua Machado de Assis, 255, 97050-450, Menino Jesus, Santa Maria, RS, Brasil.

renata.cocco@yahoo.com.br

**** Aluna do Curso de Arquitetura e Urbanismo da Universidade Federal de Santa Maria (UFSM). Bolsista do grupo de pesquisa nacional Quapá-SEL II, Núcleo Santa Maria. Rua Capitão Vasco da Cunha, 21, 97030-110, Boi Morto, Santa Maria, RS, Brasil.

leticiadurlofotografia@gmail.com

***** Aluno do Curso de Arquitetura e Urbanismo da Universidade Federal de Santa Maria (UFSM). Bolsista do grupo de pesquisa nacional Quapá-SEL II, Núcleo Santa Maria. Rua 7 de Setembro, s/n, 95800-000, caixa postal 89, Venâncio Aires, RS, Brasil.

ikefs@ig.com.br

****** Aluno do Curso de Arquitetura e Urbanismo da Universidade Federal de Santa Maria (UFSM). Bolsista do grupo de pesquisa nacional Quapá-SEL II, Núcleo Santa Maria. Rua Tuiuti, 1.181, apart. 504, 97015-661, Nossa Senhora de Fátima, Santa Maria, RS, Brasil.

marcosgiovelli@gmail.com 


\section{RESUMO}

O presente artigo visa apresentar os multimétodos de caracterização e análise dos espaços livres intraurbanos (ELIUs) públicos de Santa Maria (RS) de maneira a contextualizar e divulgar as metodologias organizadas e em fase inicial de aplicação pelo grupo Quapá-SEL II - Núcleo Santa Maria. Parte-se da categorização, espacialização e caracterização dos ELIUs públicos para o entendimento da dinâmica da vida pública. Na sequência o artigo busca explanar sobre a etapa operacional da pesquisa, ilustrando o procedimento de análise com caracterização dos arranjos formais e funcionais, das apropriações, dos comportamentos e das interações dos usuários dos Espaços Livres Intraurbanos de Lazer e Recreação (ELIULRs) e Espaços Livres Intraurbanos de Circulação (ELIUCs) - todos ilustrados com tabelas, imagens e mapas -, além da apresentação dos quatro métodos utilizados: três quantitativos, com e sem interação dos usuários, e um qualitativo com interação dos usuários, que seguem o mesmo protocolo - o estudo minucioso atento às variáveis temporais, sociais e físico-ambientais. Tendo em vista a compreensão da dinâmica social e caracterização dos elementos naturais e construídos dos ELIUs públicos, ao serem ancorados numa sistemática, é lançada uma base para o aprofundamento do conteúdo obtido como forma de reverter condições precárias de planejamentos urbano e paisagístico dos atuais espaços livres intraurbanos do município. As metodologias podem ser replicadas em outras categorias de ELIUs públicos e em outras cidades. Almeja-se promover diretrizes de projetos urbano-paisagísticos qualificados em termos de recreação, lazer, circulação e promoção de coletividade e cidadania, atendendo necessidades reais da comunidade santa-mariense e potencializando as condições do meio físico-ambiental.

Palavras-chave: Multimétodos. Espaço Público. Espaço Urbano. Espaços Culturais. Espaços Livres Intraurbanos de Lazer e Recreação. Espaços Livres Intraurbanos de Circulação.

\section{ABSTRACT}

This article aims to present and contextualize a multi-method approach for characterizing and analyzing public intraurban free spaces (IUFS). The methodology springs from the premise that the categorization, spatialization and characterization of IUFSs contribute to our understanding of the dynamics of public life. The operational stage of the methodology is described, including characterization of formal and functional arrangements, appropriations, behaviors and interactions between users of both circulation and recreational IUFSs. Three of the methods are quantitative with and without user interaction and one is qualitative with user interaction. The data collected will aid designers to revert precarious urban planning and landscape conditions currently observed in the city. The methods can be replicated with other categories of public IUFSs and in other cities, aiming to promote landscape design guidelines qualified in terms of recreation, leisure, and thus promoting real needs of the community and the physical environmental.

Keywords: Multimethods. Public Space. Cultural Spaces. Recreational Intraurban Free Spaces. Circulation Intraurban Free Spaces.

\section{INTRODUÇÃO}

A pesquisa no âmbito do paisagismo urbano contemporâneo oferece a oportunidade de estudar os Espaços Livres Intraurbanos (ELIUs), uma vez que se constituem como condicionantes primordiais para a qualidade de vida urbana e ambiental por promover a valorização de recursos ecológicos, culturais, estéticos, funcionais, históricos, econômicos, sociais e recreativos.

Como o Brasil é um país com grande diversidade paisagística e cultural, intui-se que sejam igualmente variados, em termos de tipologia e escala, os seus Espaços Livres Urbanos. Nesse sentido, o grupo Quapá-SEL II, vinculado ao Laboratório da 
Paisagem (PARQ) do Curso de Arquitetura e Urbanismo da Universidade Federal de Santa Maria (CAU-UFSM), pretende apresentar a metodologia de trabalho utilizada pelo mesmo para caracterizar e analisar os ELIUs de Santa Maria (RS). Salienta-se que esse núcleo de pesquisa local também visa dialogar com a rede nacional de pesquisa, desencadeada pelo Laboratório da Paisagem (LabParc) da Faculdade de Arquitetura e Urbanismo da Universidade de São Paulo (FAAUUSP), que propõe a formação de uma rede nacional de estudos sobre o paisagismo através da criação de núcleos regionais de pesquisa sintonizados em um mesmo referencial teórico e conceitual. O Quapá-SEL II tem se debruçado sobre a discussão acerca do Sistema de Espaços Livres (SEL) das cidades brasileiras metropolitanas, litorâneas e de médio porte em sua configuração morfológica, caracterização físico-ambiental e de apropriação socioespacial, enfatizando a sua importância para o planejamento, o projeto e a gestão da paisagem.

A exemplo da maioria das cidades brasileiras, O SEL de Santa Maria é resultante de um planejamento voltado estritamente à malha urbana edificada, a qual não reconhece tampouco potencializa o papel dos espaços livres urbanos. (MAGNOLI, 2006b). Mesmo carecendo de estrutura, manutenção, conservação e políticas públicas específicas, os espaços livres, especialmente os públicos, apresentam-se essenciais para a comunidade santa-mariense, o que é facilmente constatado pela sua ampla utilização. Uma das áreas de maior relevância para o ELIU é o centro de Santa Maria, caracterizado pela presença de espaços livres públicos "tradicionais", como praças e avenidas, boulevards e vias, estes predominantemente destinados à circulação viária ancorada no uso do veículo particular. Apesar da fácil acessibilidade por diferentes grupos sociais, são tratados pelo poder público de maneira desarticulada e sem comprometimento com a sua qualidade paisagística e/ou compatibilidade programática de atividades necessárias aos usuários. Na sequência de evolução urbana, outros ELIUs fundamentais para a cidade foram criados e/ou consolidados. Na zona central, o parque Itaimbé. Na zona leste, o campus da Universidade Federal de Santa Maria (UFSM). Na zona oeste, o parque Jockey Club. Esses locais apresentam problemáticas similares às encontradas nos demais ELIUs centrais (citados anteriormente) e são espacialmente desconexos, fato que dificulta o equilíbrio entre as diferentes funções da cidade. Em Santa Maria também não existem parques ambientais e lineares configurados por redes de corredores verdes - de forma a promover a efetividade dos SEL a partir de seus atributos funcionais, de conservação ambiental e integração social. (LIMBERGER; PIPPI; LAZAROTTO, 2007; MACEDO, 2012; PIPPI, 2014; PIPPI; TRINDADE, 2013; TÂNGARI; ANDRADE; SCHLEE, 2009).

É de extrema importância um maior entendimento dos ELIUs de Santa Maria por meio da caracterização e análise mais detalhadas de suas características naturais, construídas e de apropriação sociocultural. Pretende-se, assim, promover subsídios à proposição de diretrizes para a constituição efetiva de um SEL e a requalificação projetual dos ELIUs. 


\section{PROCEDIMENTO PARA ATUALIZAÇÃO DA ETAPA OPERACIONAL DE CARACTERIZAÇÃO E ANÁLISE DOS ESPAÇOS LIVRES INTRAURBANOS PÚBLICOS DE SANTA MARIA (RS)}

Considerando o trabalho desenvolvido pelo núcleo local Quapá-SEL desde 2006, a fase atual da pesquisa, além de recorrer às etapas teórico-conceitual e contextual (LIMBERGER; PIPPI, LAZAROTTO, 2007; PIPPI et al., 2009), atualizou a etapa operacional para utilização de multimétodos de coleta de informações e investigação sobre os ELIUs. O propósito dessas alterações é verificar as atuais condições físico-ambientais dos ELIUs santa-marienses e enfocar a dinâmica da vida pública. (CARMONA; MAGALHÃES, 2008; CARMONA et al., 2003, 2010; GEHL, 2008, 2010, 2011, 2014; GEL; GEMZØE, 1996; GEHL; SVARRE, 2013; MAGNOLI, 2006b; OKAMOTO, 2002; PIPPI, 2014; WHITE, 1980;). Isso para proceder (aqui se enfatiza o ineditismo e o pioneirismo da atuação do grupo Quapá-SEL local) com a análise cruzada de dados - via Sistema de Informações Geográficas (SIG) - oriundos tanto da caracterização dos arranjos da forma e das funções, quanto das apropriações, comportamentos e interações dos usuários dos Espaços Livres Intraurbanos Públicos de Lazer e Recreação (ELIULRs) e Espaços Livres Intraurbanos Públicos de Circulação (ELIUCs).

A estrutura da etapa operacional organiza-se de acordo com os itens abaixo, o que não implica necessariamente a realização desses procedimentos de forma sequencial:

a. definir o grupo dos ELIULRs e ELIUCs a serem caracterizados e analisados;

b. organizar, com a contribuição do poder público municipal, um banco de imagens aéreas georreferenciadas dos ELIUs públicos a pesquisar;

c. atualizar e ampliar o banco de dados dos ELIUs públicos para levantar e mapear aspectos físico-ambientais, paisagísticos, modos de utilização e tipos de apropriação social de modo a analisar as redes sociais e pontes sociais de integração, os comportamentos e coesão social, a localização e os raios de atendimento;

d. (re)elaborar planilhas e questionários de caracterização estrutural-espacial, morfológica, funcional, ambiental-paisagística e social, utilizando multimétodos com dados quantitativos e qualitativos para a posterior análise dos ELIULRs e ELIUCs públicos;

e. coletar dados in loco por pesquisadores do Quapá-SEL local e colaboradores (estudantes de graduação e pós-graduação) conforme a observação rigorosa do protocolo de pesquisa dos ELIUs públicos;

f. tabular as informações obtidas em SIG com a utilização do ArcMap 10.2 e de estatística descritiva;

g. elaborar mapas temáticos que ilustrem e consubstanciem as análises realizadas com a interpolação de dados físico-ambientais, sociais, comportamentais e locacionais para cada e/ou entre um mesmo grupo de ELIULR e ELIUC públicos;

h. efetuar a análise particular dos resultados de cada método (potencialidades e 
limitações) e a do cruzamento dos métodos quantitativos e qualitativos (potencialidades e limitações);

i. elaborar diretrizes de planejamento, gestão e critérios de projeto a partir das caracterizações e análises realizadas - avaliações - para os ELIULRs e ELIUCs públicos.

\section{DEFINIÇÃO DAS CATEGORIAS DE ELIUS PÚBLICOS}

Os ELIUs foram organizados com base em estudos anteriores de classificação (PIPPI et al., 2011) em distintas categorias tipológicas. Entre as quais:

- categoria das Áreas de Lazer e Recreação (conforme o domínio);

- categoria das Áreas de Circulação (conforme a mobilidade);

- categoria das Áreas de conservação, preservação, proteção dos recursos naturais, proteção dos recursos culturais e históricos (conforme a conectividade);

- categoria das Áreas de Produção e Serviço (conforme a produtividade urbana);

- categoria das Áreas Institucionais/Educacionais (conforme a necessidade educativa);

- categoria das Áreas com Potenciais de Utilização (conforme a potencialidade).

Para a realização da pesquisa em campo foram elencados nove ELIUs. Destes, seis incluem-se na categoria de lazer e recreação - parques e praças - e três estão classificados conforme a categoria de circulação, ou seja, canteiros centrais, ciclovias e pistas multiuso.

\subsection{CATEGORIA DE LAZER E RECREAÇÃO (CONFORME O DOMÍNIO)}

Sobre a categoria ELIULR, entende-se por "lazer" (do latim, licere) tudo aquilo que pode ser feito, no tempo livre, para o desenvolvimento de atividades prazerosas'. Assim, as áreas destinadas ao lazer e à recreação de domínio público promovem a integração entre pessoas de distintas faixas etárias e classes sociais, inferindo que significados, tanto individuais quanto coletivos, são elaborados pela comunidade, relacionando-os ao tempo livre que se dispõe para o desempenho de tarefas habituais. Conforme Marcellino:

O lazer possui um caráter "revolucionário", pois é no tempo de lazer, onde procuram a vivência de algumas coisas pela escolha e satisfação, encontro com pessoas, com o "novo" e o "diferente", que se encontram possibilidades de questionamento dos valores da estrutura social, e das relações entre sociedades e espaço. (MARCELLINO apud PELLEGRIN, 1996, p. 33).

HOUAISS, 2010 
Os termos lazer e recreação são polissêmicos, porém é basilar serem claramente diferidos sob o ponto de vista científico, apesar do casual emprego linguístico. Considera-se a categoria de lazer e recreação como uma variedade de atividades que podem ser realizadas coletiva ou individualmente em horas vagas de lazer, sendo elas ativas e/ou passivas. São espaços que proporcionam prática de esportes, socialização, cultura e movimento corporal humano para uma determinada população que os desenvolve de modo espontâneo. É o que se define como atividades em espaços de lazer e recreação, podendo abranger funções diversas, como educativa, social, pessoal ou até de controle. Já por "recreação", palavra oriunda do termo recreare (latim), entende-se o seu significado relacionado ao ato de "recriar, restaurar". Desse modo, aproximando-o da categoria ELIULR, pode-se compreendê-lo como parte de uma ferramenta socialmente capaz de promover elos interpessoais de diferentes caracteres. Portanto, a recreação teria como ponto de partida a potencialidade de uso, apropriação e identificação dos usuários, sendo esses espaços, por exemplo, de descanso, distração, recreios ou pausas no tempo de trabalho.

Os ELIUs foram classificados e categorizados conforme seu domínio público (parque de bairro e de vizinhança, parque de bolso, praça, rua, passeio público, campo de futebol, quadra poliesportiva, calçadão, largo, balneário e praia) e privado (clube, sede campestre, balneário, condomínio fechado, parque temático e centro desportivo). Essas categorias de domínio se distribuem morfológica e espacialmente de forma hierárquica na cidade. Sendo assim, aplicam-se os questionários com o intuito de extrair a forma de utilização e apropriação dos usuários das áreas de uso público e privado destinadas à integração entre pessoas e dessas com o meio ambiente.

Conforme Macedo et al. (2009, p. 71), os parques e as praças são os tipos de ELIU mais comuns do Brasil. Existe uma tendência cultural de maior grau de importância destinada a eles, "[...] uma cultura do poder público e da população em reconhecer e demandar, predominantemente as praças [...]", como ELIUs simbólicos e preferidos para utilização pública, bem como forte demanda de investimentos públicos de criação, gestão e manutenção desses espaços. Dos 81 ELIUs públicos de Santa Maria, a maior parte é de lazer e recreação, representada por parques e praças localizados na área central, configurando maior abrangência de atendimento quanto a essa categoria de utilização - embora seja o oposto em áreas periféricas, com menor abrangência, tamanho e número.

\subsection{CATEGORIA DE CIRCULAÇÃO (CONFORME A MOBILIDADE): ELIUC}

O deslocamento ou movimento do homem está relacionado a percepções sinestésicas, principalmente visuais, conectadas a fatores como temperatura, vento, textura, policromia, intensidades luminosa e sonora, microclima e nuances da paisagem, as quais promovem grande quantidade de experiências sensoriais. Desse modo, a categoria ELIUC ilustra a possibilidade de ocorrência da circulação humana vinculada ou 
não a usos múltiplos de lazer, recreação, turismo, educação ambiental, patrimonial e conectividade ecológica por meio dos processos bióticos e abióticos. Assim, os ELIUCs contribuem para conectividade estrutural do SEL das cidades e permitem a integração entre outras categorias tipológicas de ELIUs.

Entre os tipos de categorias de circulação estão os parques lineares, boulevards, canteiros centrais, pistas multiuso e compartilhadas, ciclovias, ciclofaixas, cinturões verdes, corredores permeáveis: verdes (vegetação), azuis (recursos hídricos), amarelos (linha da preamar, dunas, estuários e lagoas); corredores impermeáveis: pretos (asfalto), cinza (cimento e concreto), redes e corredores ecológicos. Tanto as redes como os diversos tipos de corredores possuem fluxo antrópico ou biótico, que se dão de forma contínua, fragmentados ou interrompidos. Outro tipo de circulação em áreas urbanas densas são os skyways, corredores aéreos que, segundo Turner (1995), são compostos por corredores suspensos nas superfícies das coberturas das edificações, que permitem o deslocar em lugares calmos e ensolarados. Ademais, as categorias de circulação, na maioria das vezes, possuem ou não dissociação do movimento veicular, sujeito a questões de segurança, conservação e/ou preservação.

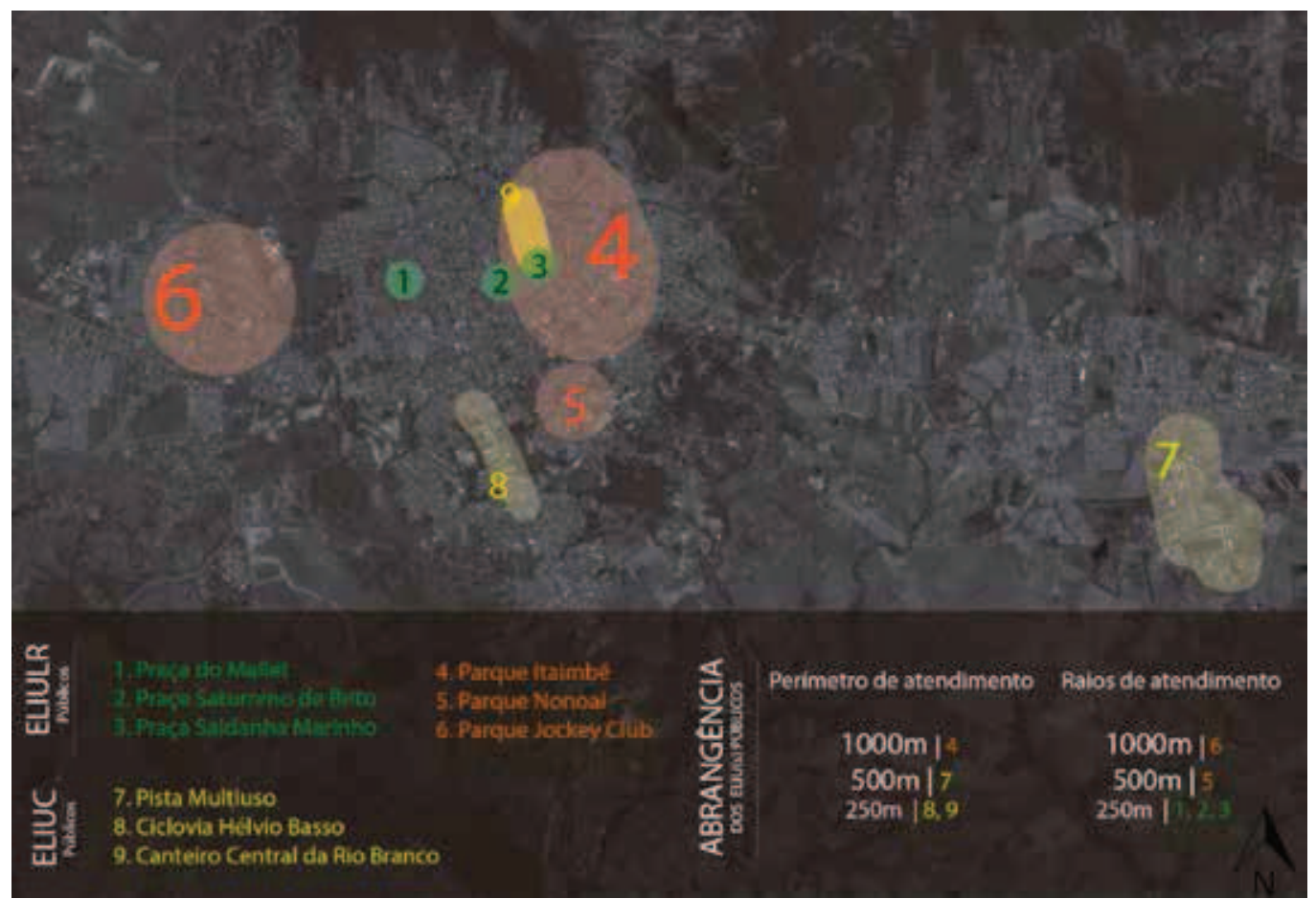

Figura 1 Mapa dos ELIUs públicos nas categorias Lazer e Recreação e Circulação.

Fonte: Imagem aérea (2008) georreferenciada, cedida pela Prefeitura Municipal de Santa Maria. Editada por Letícia Durlo. Arquivo do grupo Quapá-SEL II, núcleo Santa Maria, 2015.

Integrada às duas categorias de ELIU, de lazer e recreação e de circulação, encontra-se uma amostra dos ELIUs públicos santa-marienses sobre os quais é possível questionar a qualidade, a funcionalidade e a apropriação, pois muitos, de fato, não existem: ora são lugares ociosos e/ou degradados, sem infraestrutura ou equipamentos instalados, ora 
são fragmentos de parcelamentos urbanos destinados a áreas públicas não vinculadas ao planejamento e/ou à gestão urbana e ambiental. Consequentemente, apresentam diversos problemas de utilização (em alguns, predominam ações de vandalismo e tráfico de drogas), como falta de observação às reais e atuais necessidades dos usuários, abandono e precariedade da estrutura física e de infraestrutura.

Para elencar os mais significativos ELIUs na atual fase de pesquisa, optou-se por selecionar seis ELIUs públicos, na categoria de Lazer e Recreação, e três na categoria de Circulação (figura 2). A seleção foi criteriosa, a fim de cobrir diferentes zonas do perímetro urbano, atingir distintos perfis socioeconômicos da população santa-mariense, considerar as escalas (o que abarca tamanho e proporção), a localização na estrutura urbana (destaca-se a região da cidade e nos raios de atendimento e/ou abrangência para usufruto da população, por exemplo, e cumprir diferentes funções), as categorias tipológicas (quadros 1 e 2) descritas por Pippi et al. (2011) a partir de distinções dadas pelo domínio (enfatizando a propriedade pública), pela função exercida, a fim de propiciar circulação urbana, conectividade paisagística e ecológica, educação patrimonial e utilização social em termos de recreação e lazer, saúde física e mental, produção econômica.

\subsection{CATEGORIA LAZER E RECREAÇÃO (ELIULR) 2}

\subsubsection{GRUPO 1: PRAÇA - O CASO DA PRAÇA GENERAL OSÓRIO (MALLET)}

Tabela 1 Ambiência da Praça General Osório (Mallet)

\begin{tabular}{l|l}
\hline \multicolumn{1}{c|}{ ELIULR } & \multicolumn{1}{c}{ Praça General Osório (Mallet) } \\
\hline Caracterização & $\begin{array}{l}\text { Espaço livre de propriedade pública mantido e vigiado pelo exército } \\
\text { brasileiro. Ainda conserva, em grande parte, sua linha projetual } \\
\text { paisagística modernista, embora tenha sofrido acréscimo pela } \\
\text { intervenção de uma pista de caminhada. }\end{array}$ \\
\hline Conflitos & $\begin{array}{l}\text { Conservação atual precária, apresentando problemas de drenagem, } \\
\text { o que compromete sua utilização. }\end{array}$ \\
\hline Potencialidades & $\begin{array}{l}\text { Layout compositivo interessante. Vegetação arbórea e mobiliário } \\
\text { abundantes e com boa distribuição. }\end{array}$ \\
\hline Usos Públicos & $\begin{array}{l}\text { Lazer e recreação (playground, pista para caminhada e quadras } \\
\text { poliesportivas) e usos cívicos-militares. Ocorrem comércios informal } \\
\text { e formal temporários (feira de hortifrutigranjeiros). Na avenida Liber- } \\
\text { dade, situada à frente da praça, acontece o carnaval de rua. }\end{array}$ \\
\hline
\end{tabular}

Fonte: Arquivo do grupo Quapá-SEL II, núcleo Santa Maria, 2015.

2 Ver a descrição dos demais ELIULRs em apêndice. 


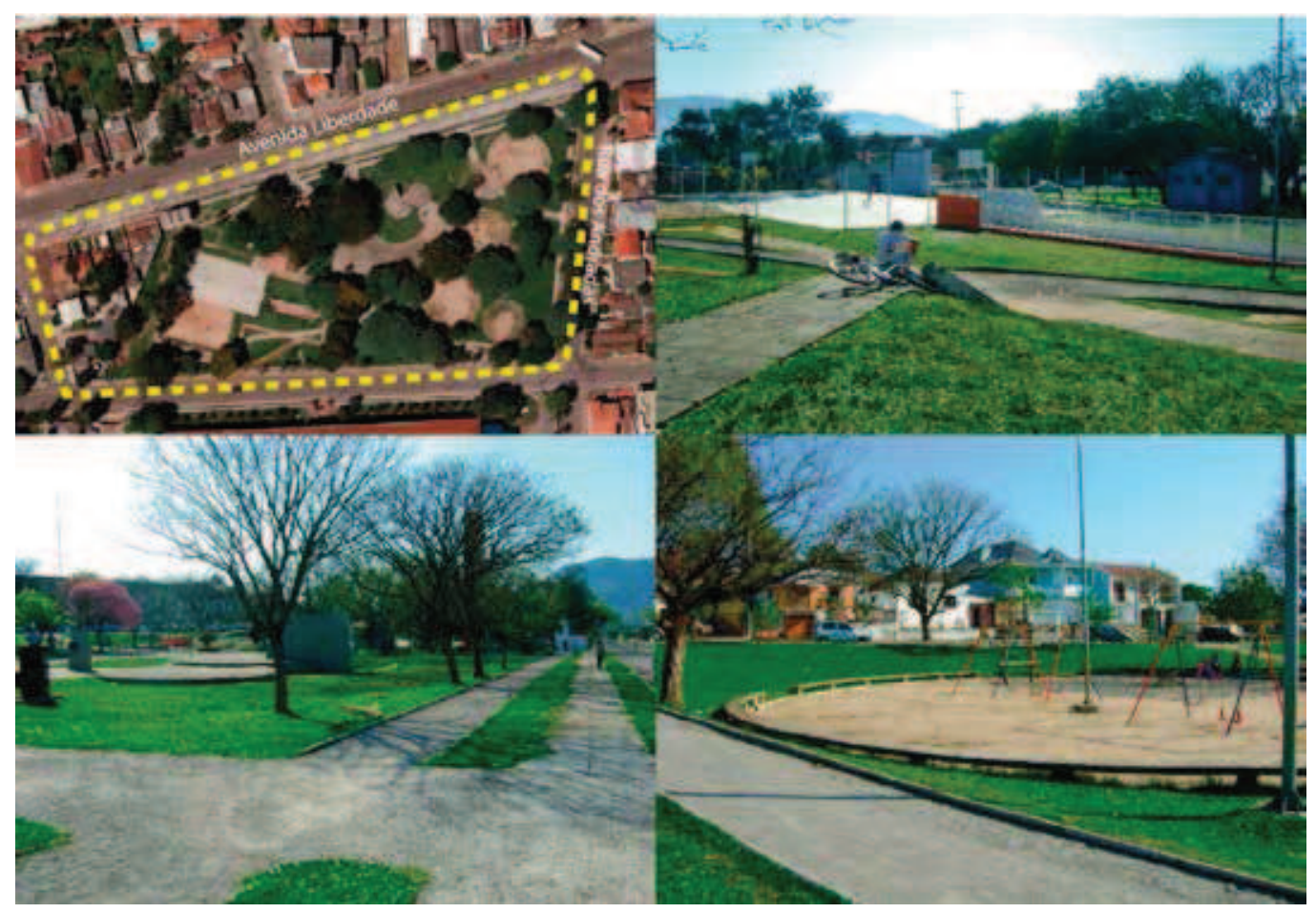

Figura 2 ELIULR - Praça General Osório (Mallet).

Fonte: Arquivo do grupo Quapá-SEL II, núcleo Santa Maria, 2015.

\subsubsection{GRUPO 2: PARQUE - O CASO DO PARQUE ITAIMBÉ}

Tabela 2 Ambiência do Parque Itaimbé

\begin{tabular}{l|l}
\hline \multicolumn{1}{c|}{ ELIULR } & \multicolumn{1}{c}{ Parque Itaimbé } \\
\hline Caracterização & $\begin{array}{l}\text { O maior parque público da zona central da cidade. Anterior à sua existência, } \\
\text { possuía o arroio Itaimbé, hoje canalizado. Abrange grande público, usuários } \\
\text { de distintas faixas etárias e múltiplas atividades desenvolvidas nas quadras } \\
\text { poliesportivas, no playground, nas áreas de gramado sob a sombra, eventos } \\
\text { do cenário musical independente na concha acústica, além da utilização de } \\
\text { um bar/lancheria que ocupa uma das estruturas físicas do parque. }\end{array}$ \\
\hline Conflitos & $\begin{array}{l}\text { Devido à insegurança e ao estado atual de má conservação, tornou-se um } \\
\text { grande espaço para ocorrência de crimes, principalmente tráfico e uso de } \\
\text { drogas. Apresenta-se como área perigosa para o entorno em virtude da falta } \\
\text { de iluminação. Quadras e banheiros encontram-se depredados e há desuso } \\
\text { do espaço Bombril, destinado para apresentações multiculturais. }\end{array}$ \\
\hline Potencialidades & $\begin{array}{l}\text { Por ser o maior parque da cidade em termos de área verde, o local tem } \\
\text { potencial para eventos culturais, práticas de esporte, lazer e contemplação. }\end{array}$ \\
\hline Usos Públicos & Convívio social, recreação, comércio, práticas desportivas. \\
\hline
\end{tabular}

Fonte: Arquivo do grupo Quapá-SEL II, núcleo Santa Maria, 2015. 


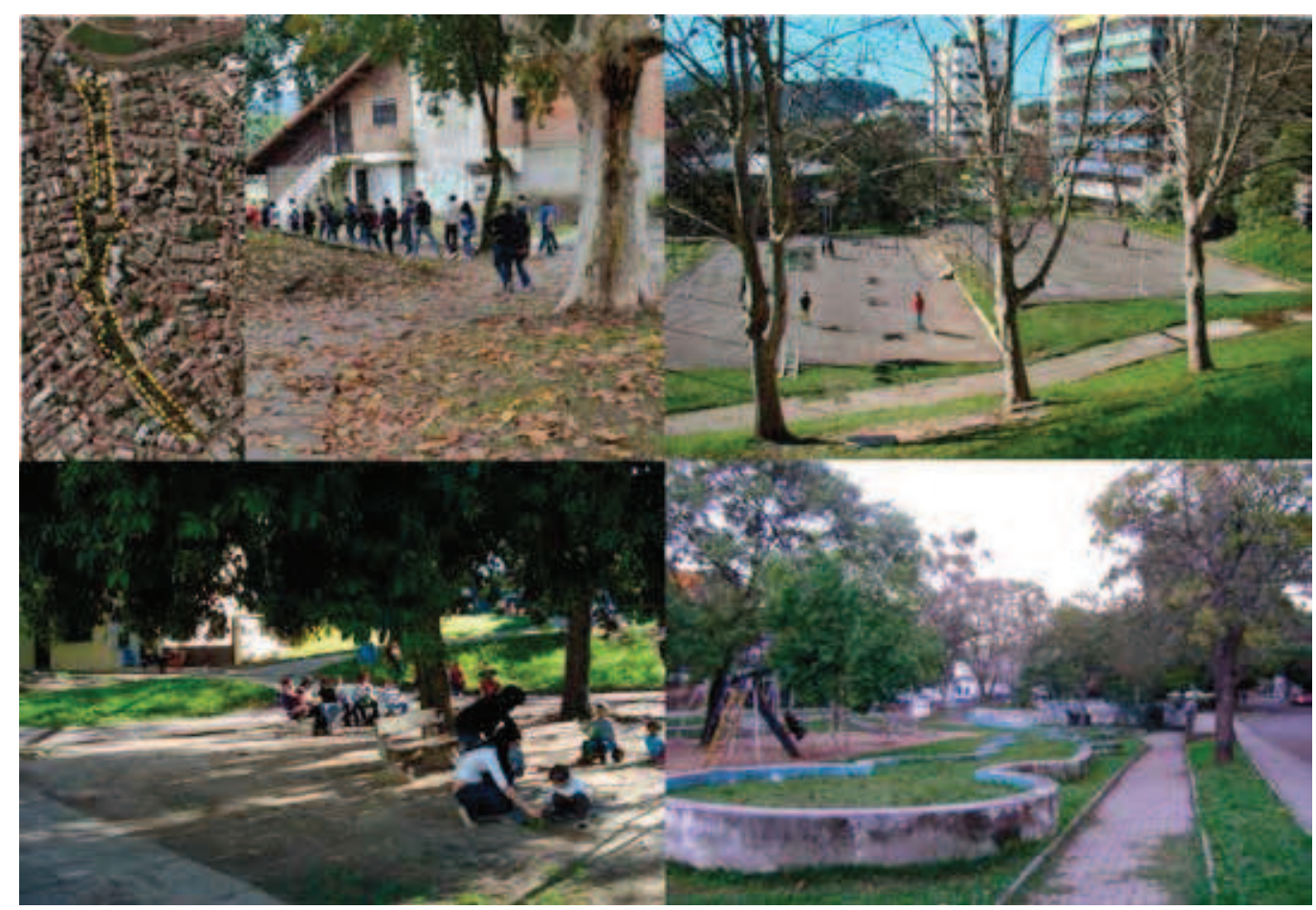

Figura 3 ELIULR - Parque Itaimbé.

Fonte: Arquivo do grupo Quapá-SEL II, núcleo Santa Maria, 2015.

\subsection{CARACTERIZAÇÃO DA CATEGORIA CIRCULAÇÃO (ELIUC) ${ }^{3}$ \\ 3.4.1 GRUPO 3: CANTEIROS CENTRAIS, CICLOVIAS E PISTAS MULTIUSO - O CASO DO CANTEIRO CENTRAL DA AVENIDA RIO BRANCO}

Tabela 3 Ambiência do Canteiro Central da avenida Rio Branco

\begin{tabular}{l|l}
\hline \multicolumn{1}{c|}{ ELIUC } & \multicolumn{1}{c}{ Canteiro Central da avenida Rio Branco } \\
\hline Caracterização & $\begin{array}{l}\text { Criado no final do século XIX, possui importância histórico-cultural para a } \\
\text { cidade por mediar a ligação viária da área central (praça Saldanha Marinho) } \\
\text { com a então Estação Ferroviária. Ainda hoje, apresenta-se como um dos } \\
\text { principais eixos de ligação norte-sul do município. }\end{array}$ \\
\hline Conflitos & $\begin{array}{l}\text { A requalificação do espaço foi feita de maneira precária, resultando em } \\
\text { mobiliário urbano anacrônico ao contexto citadino; anteriormente, possuía } \\
\text { comércio informal de camelôs, que foram realocados para reativar o uso } \\
\text { contemplativo (não efetivado). Seu uso original foi perdido e encontra-se } \\
\text { degradado. }\end{array}$ \\
\hline
\end{tabular}

3 Ver a descrição dos demais ELIUCs em apêndice. 


\begin{tabular}{l|l}
\hline Potencialidades & $\begin{array}{l}\text { É o grande bulevar da cidade e poderia ser ponto de encontro dos santa- } \\
\text {-marienses. Com potencial patrimonial por meio do eixo histórico, espaços de } \\
\text { convívio e turístico. }\end{array}$ \\
\hline Usos Públicos & $\begin{array}{l}\text { Comércio formal (taxistas), local de circulação e, em alguns trechos, ponto de } \\
\text { encontro para práticas culturais, como a do chimarrão. }\end{array}$ \\
\hline
\end{tabular}

Fonte: Arquivo do grupo Quapá-SEL II, núcleo Santa Maria, 2015.

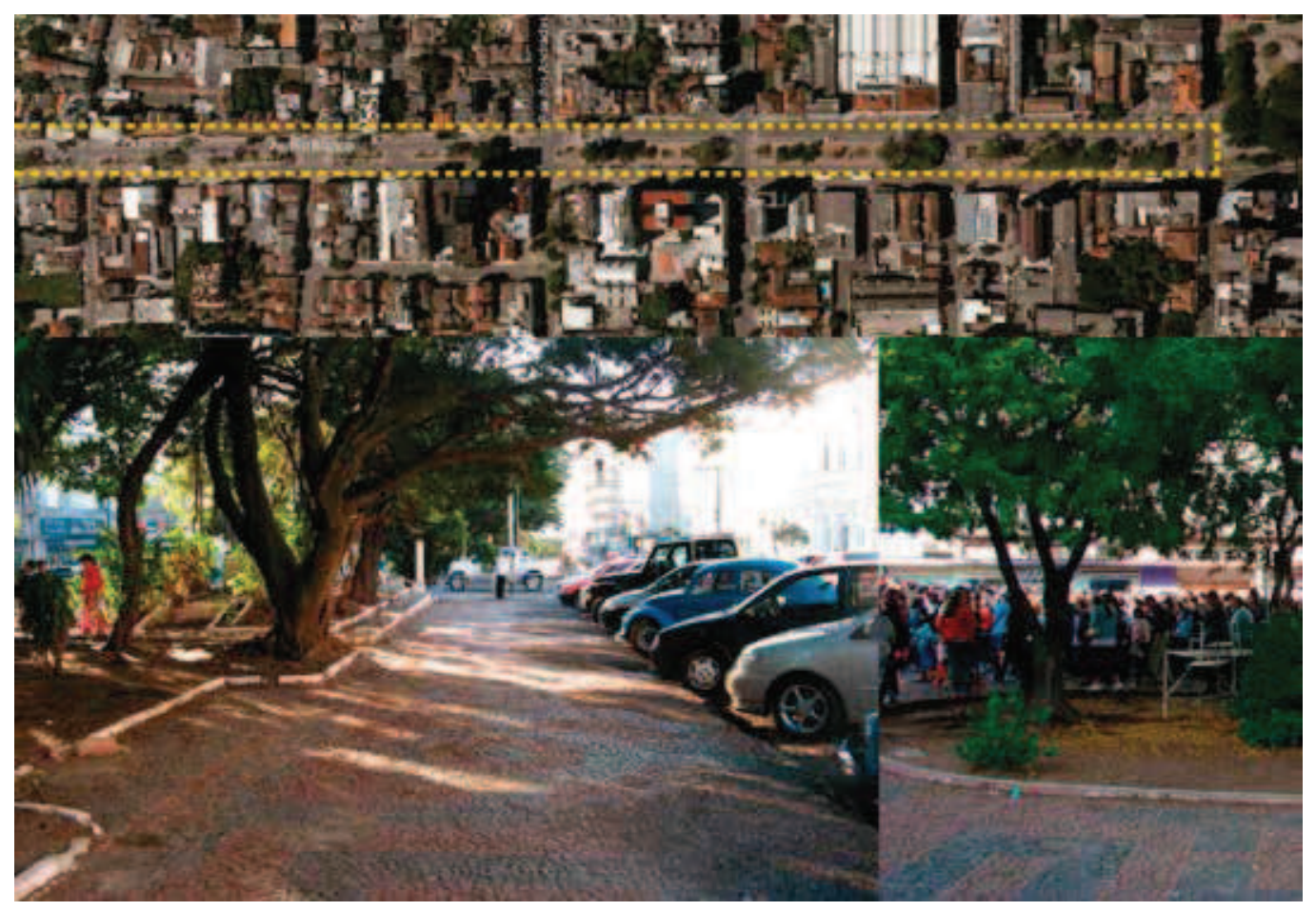

Figura 4 ELIUC - Canteiro Central da avenida Rio Branco.

Fonte: Arquivo do grupo Quapá-SEL II, núcleo Santa Maria, 2015.

\section{ESTRATÉGIAS METODOLÓGICAS PARA ANÁliSE DOS ELIUS PÚBLICOS COM MULTIMÉTODOS}

Para medir e avaliar o ambiente físico-ambiental e social dos ELIUs públicos, vem se utilizando métodos de pesquisa quantitativos e qualitativos. A fim de identificar os fenômenos de uso/apropriação e a frequência de ocorrência, pretende-se correlacionar as relações sociais com o ambiente natural e construído para propiciar informações válidas e confiáveis em um pequeno período de tempo - uma vez que ambos os paradigmas, objetivo e subjetivo, estão sendo coletados concomitantemente nos ELIUs de Santa Maria, conformando o panorama de multiestudos de caso.

O estudo de caso consiste na investigação empírica de um tópico ou fenômeno, de forma a alcançar a melhor compreensão entre análise e contexto e atingir precisão de informações, não se restringindo à utilização de uma simples fonte de informação ou 
de única técnica. Geralmente, quando empregados como maneira de investigação, os multimétodos permitem comparar eficazmente dois ou mais tipos de estudos de caso entre si e por similaridade e/ou contraste.

Essa é uma estratégia importante de pesquisa, porque visa ao maior entendimento do ambiente físico-ambiental a ser analisado (pela caracterização dos recursos naturais e construídos no contexto e no entorno imediato) e das complexidades sociais do fenômeno - em termos de número de usuários (gênero, idade, tipos de atores sociais), usos e apropriações, interações e comportamentos e teias de redes sociais nos ELIUs. Dessa forma, é possível "humanizar" os dados quantitativos pela conexão de dados estatísticos com dados reais vivenciados na dinâmica social da vida pública.

São características das análises a partir de multimétodos a coleta de dados extensiva, na qual os pesquisadores podem se utilizar de diferentes e complementares técnicas de abordagem, como observações, entrevistas, análise documental e registro audiovisual (fotografia, gravação de vídeos e áudio). A vantagem de efetuar estudos de caso com a utilização de multimétodos está na possibilidade de obter informações oriundas das diferentes técnicas de abordagens mencionadas acima. Em contrapartida, as desvantagens estão na dificuldade e no controle da quantidade das informações coletadas pelos pesquisadores. A ausência, pelos mesmos, de uma visão global pode resultar na falta de controle das informações provenientes das fontes múltiplas de pesquisa e técnicas de abordagem, podendo resultar em falhas e conclusões equivocadas e/ou inconsistentes. (CRESWELL, 2009; GROAT; WANG, 2002; SOMMER, B.; SOMMER, R., 2002; YIN, 2003, 2009; ZEIZEL, 2006).

As análises quantitativas promovem o registro objetivo e positivista da ocorrência dos fenômenos sobre o mundo em que vivemos. De forma prévia e estruturada, para ser replicada pelos pesquisadores, as informações numéricas passam a ser mais importantes do que as palavras, permitindo a comparação e a descrição objetiva de situações ou fenômenos analisados. Já as análises qualitativas promovem entendimento mais subjetivo e construtivista da ocorrência dos fenômenos, de forma mais flexível, para obter o entendimento dos significados que as pessoas têm entre si e destas com coisas e/ou eventos, provendo uma complementaridade holística das informações coletadas, com múltiplas perspectivas, que podem trazer validade dos resultados, os quais são cruciais para estudos da complexidade social. A combinação de e entre dados quantitativos e qualitativos adiciona relevância para os resultados das análises de ELIU, pois oferecem o comparativo entre técnicas e informações. (BABBIE, 2007; LEEDY; ORMROD, 2005; PIPPI, 2014; PUNCH, 2000; YIN, 2003).

A pesquisa atual do grupo local Quapá-SEL II está baseada na utilização de multimétodos com análises quantitativas e qualitativas, promovendo informações detalhadas sobre os ELIUs públicos quanto a aspectos de caracterização físicas, ambientais, paisagísticas e sociais. Dessa maneira, desde 2014, a pesquisa reestruturou-se, agregando três novos métodos aos métodos de análise dos ELIULRs públicos e dos ELIUCs públicos. A metodologia adotada baseia-se no levantamento de dados a respeito do caráter físico-ambiental (relevo, vegetação, acessibilidade universal, mobilidade urbana, status 
de conservação/manutenção da infraestrutura, do mobiliário), cujas planilhas foram revisadas pelos pesquisadores. Para a anotação da dinâmica social nos ELIUs - amparada na observação sociocomportamental, usos/apropriações e na obtenção das impressões pessoais dos seus usuários - planilhas e questionários foram elaborados para a caracterização e interação com os mesmos.

O objetivo primordial da alteração da operacionalidade da pesquisa pretendeu, pela aplicação sistemática de diferentes métodos de análise, registrar as informações levantadas por Pippi (2014), Sommer B. e Sommer R. (2002) e Zeizel (2006): quem são os usuários? quem são os atores sociais? o que os usuários fazem? quais são as atividades mais emergentes? quais são as relações espaciais? quais são as relações sociais entre os usuários? como as características físico-ambientais afetam o uso e a apropriação do espaço? quais características físico-ambientais são preferidas pelos usuários? quais as relações entre usuários e destes com os ELIUs públicos?

O procedimento metodológico está configurado por quatro métodos. Os dois primeiros fundam-se na interação com os usuários dos ELIUs através de questionário qualitativo com perguntas abertas (método 1) e do survey quantitativo com perguntas fechadas (método 2). Os outros dois métodos, sem interação com os usuários, pautam-se pela caracterização dos aspectos sociais por meio de mapas comportamental (método 3) e de caracterização dos aspectos naturais e construídos (método 4). Cabe frisar que os métodos 1 e 2 serão analisados a partir de gráficos elaborados por meio de estatística descritiva. Já os métodos 3 e 4 serão espacializados em mapas temáticos no ArcMap 10.2.2, de modo que as informações coletadas possam ser analisadas por diagramas de estatística avançada e descritiva. Cada método será analisado, em primeira instância, separadamente e, posteriormente, triangulados entre si de forma comparativa e relacional.

A aplicação de todos os métodos segue o mesmo protocolo, especificamente criado para a análise dos ELIUs públicos: análise uma vez a cada dois meses, entre abril de 2015 e março de 2016, em um dia de semana e um fim de semana em diferentes períodos do dia - pela manhã (das $7 \mathrm{~h}$ às $11 \mathrm{~h} 59 \mathrm{~m}$ ) e pela tarde (das $12 \mathrm{~h}$ às $17 \mathrm{~h}$ ), durante uma hora por dois pesquisadores em campo. $O$ protocolo depende da anotação de variáveis, tais como:

- temporais: temperatura, condição solar e velocidade dos ventos;

- sociais: tipo de usuários (gênero e idade, tipo e número de atores sociais), frequência de uso, tipo de uso/atividade (formal e informal), complementos das atividades, nível de atividade física, existência e tipo de pontes de interação social, níveis de interação e catalisadores das interações sociais;

- físico-ambientais: zoneamento do Plano Diretor de Desenvolvimento Urbano Ambiental (PDDUA) em termos de usos, atendimento, tipo e categoria de ELIU, condicionantes físico-ambientais (relevo, vegetação e recursos hídricos, tipos de atividades, elementos complementares como estruturas físicas e máscara dos ELIUs com diferentes dados do tecido urbano e seus padrões morfológicos). 


\subsection{MÉTODO 1: QUESTIONÁRIO QUALITATIVO COM INTERAÇÃO DOS USUÁRIOS}

Este método consiste num processo pelo qual duas ou mais pessoas trocam informações e ideias baseadas em questões e respostas que resultam numa comunicação inter-relacional com construção de significados diversos e de conhecimento detalhado sobre tópicos particulares. (DI MARCO et al., 2009; ESTBERG, 2002; PATTON, 1990; ZAMANI; MLEE; PIPPI, 2014).

Para cada levantamento em campo, estipulou-se uma média de aplicações de dez questionários por pesquisador (ver apêndice). O questionário estrutura-se em sete perguntas abertas que contribuirão para a compreensão das informações referentes aos seguintes tópicos: motivações, emoções, percepções, aspectos positivos, aspectos negativos, atividades/padrões de uso e ambientes preferenciais. As informações dos questionários serão tabuladas e analisadas com estatística descritiva através da criação de categorias compostas por eixos-axiais. Os instrumentos adotados são: pranchetas tamanho A4, canetas esferográficas de cores diferentes e/ou lapiseiras.

\subsection{MÉTODO 2: SURVEY QUANTITATIVO COM INTERAÇÃO DOS USUÁRIOS}

Este método possui eficiência para o registro de diferentes informações oriundas da interação com os usuários, em que o entrevistador apresenta uma série de questões ou tópicos que precisam ser explorados, como atitudes, opiniões, preferências, motivações, pensamentos e experiências, sentimentos por ambientes, tipo de atividades/usos, comportamentos sociais e antissociais, características preferenciais dos diferentes ambientes dos espaços públicos, sugestões e ideias futuras e/ou como poderiam qualificar os ambientes, aumentando frequência e intensidade de uso. Geralmente, o questionário é composto por questões de múltipla escolha, linguagem simplificada e clara, que podem ser facilmente registradas, analisadas e tabuladas. (PIPPI, 2014; PROJECT FOR PUBLIC SPACES, 2000; ZAMANI; MLEE, PIPPI, 2014).

Para cada saída a campo, estimou-se uma média de aplicação de dez questionários por pesquisador (ver apêndice). Os tópicos (ver apêndice) utilizados no questionário do tipo survey são:

- informação geográfica (morador ou não de Santa Maria);

- informação sociodemográfica dos usuários (idade e gênero);

- razão de uso/apropriação do espaço público;

- tipo de atividades e uso;

- natureza e frequência de uso;

- tempo de permanência;

- tipo de interação social;

- natureza e frequência das interações sociais. 
Os instrumentos utilizados nesse método são: pranchetas tamanho A4, canetas esferográficas de cores diferentes e/ou lapiseiras.

\subsection{MÉTODO 3: OBSERVAÇÃO DIRETA SEM INTERAÇÃO DOS USUÁRIOS COM MAPA COMPORTAMENTAL}

Este método apresenta uma técnica de análise sistêmica de observações e registro dos usuários que relaciona a localização ocupada em um determinado ambiente por um período de tempo com as atividades desenvolvidas, pontos de maior e/ou menor utilização, relacionamento com ambiente natural e construído e entre usuários. O foco específico desse tipo de análise baseia-se na avaliação de padrões de uso e apropriação em cada ambiente do ELIU público. Tal método informa importantes diretrizes de planejamento, de requalificação projetual e gerenciamento dos espaços públicos. (DI MARCO et al., 2009; PROJECT FOR PUBLIC SPACES, 2000; SOMMER, B.; SOMMER, R., 2002).

As informações do levantamento de campo serão processadas, especializadas e analisadas em Sistema de Informações Geográficas (SIG) com utilização do programa de geoprocessamento ArcMap 10.2.2, o qual propiciará a criação de mapas temáticos e gráficos. Posteriormente, serão realizadas análises estatísticas dos resultados.

As variáveis (humanas, comportamentais e sociais) utilizadas neste método de observação direta seguem abaixo:

- tipo de usuário (gênero e idade);

- tipo de atores sociais (células sociais);

- categorias de utilização do ELIU público;

- padrão de uso/tipo de atividades (formais e/ou informais);

- tipo de atividades complementares;

- níveis de atividade física;

- ocorrência de pontes de integração social;

- tipos de pontes de integração social;

- níveis de interação social;

- catalisador das interações sociais.

O mapa comportamental consiste em observações realizadas de forma dinâmica e cinética por parte do pesquisador, de modo a observar e coletar as variáveis sociais envolvidas dos ELIUs públicos com anotações do tipo check-list, observações descritivas e registro fotográfico. Essa técnica permite um completo e detalhado entendimento da esfera pública e social. A população participante da pesquisa observacional são todos os usuários dos espaços públicos - observados sem nenhuma interação e/ou contato com a equipe de pesquisadores. (PIPPI, 2014; ZAMANI; MLEE; PIPPI, 2014).

Os instrumentos utilizados nesse método são: pranchetas tamanho A4 e A3, canetas esferográficas de cores diferentes e/ou lapiseiras, mapa base de imagem aérea 
ortorretificada com alta resolução, papel vegetal e máquina fotográfica Canon EOS Digital Rebel XS/EOS 1000D.

\subsection{MÉTODO 4: CARACTERIZAÇÃO DOS ELIUs PÚBLICOS}

Este método consiste na utilização de fichas de análise das características físico-ambientais e formais dos ELIUs públicos cujas informações levantam os componentes naturais, os elementos construídos, suas modalidades e potencialidades de utilização bem como função, estado de conservação e caracterização de seu entorno imediato. (DI MARCO et al., 2009; PIPPI, 2014). Os tópicos (ver apêndice) utilizados nesse método são:

- zoneamento PDDUA e mapas temáticos: usos, raios de atendimento, morfologia espaços livres e categorização dos espaços livres;

- categorização dos condicionantes físico-ambientais: relevo, vegetação, recursos hídricos;

- análise e descrição dos ELIUs: função, utilização, atividades associadas, tipo de atividades/padrões de uso, presença de edificações, forma de manutenção e tipos de atuação pelos agentes;

- elementos complementares/estruturas físicas: tipos de modais urbanos, tipos de mobilidades, tipos de estruturas físicas (fixos e/ou temporários), tipos de mobiliários urbanos, manutenção, infraestrutura urbana, tipo de revestimentos de piso, principais usuários, relação social/ambiental, segurança e visibilidade;

- máscara dos ELIUs/análise morfológica do tecido urbano: verticalização, alturas, densidade, funções e usos, revestimentos de piso, tipo de vias, fluxos do entorno e acessos.

Os instrumentos utilizados nesse método são: pranchetas tamanho $A 4$, canetas esferográficas e/ou lapiseiras e máquina fotográfica Canon EOS Digital Rebel XS/EOS 1000D.

\section{CONSIDERAÇÕES FINAIS}

O presente artigo relatou a continuidade do projeto de pesquisa, reestruturado a partir de 2014, com uma nova equipe de pesquisadores atuantes na rede nacional Quapá-SEL II. O núcleo local reviu a metodologia de pesquisa dos ELIUs para a etapa operacional a ser realizada em Santa Maria (RS). As categorias de ELIU (Lazer e Recreação e de Circulação), os multimétodos de pesquisa e o protocolo de aplicação em campo foram apresentados e podem ser replicados em outros ELIUs públicos, no Brasil e em outros países.

Ao reelaborar a metodologia de pesquisa, o grupo santa-mariense pretendeu contribuir para a criação de métodos inovadores - em relação à coleta de dados quantitativos e qualitativos - para caracterização e análise físico-ambiental e social dos 
ELIUs públicos. Ao propor a integração das análises - justamente porque os resultados obtidos em cada método serão posteriormente cruzados entre si -, acredita-se em poder oferecer informações cruciais para a elaboração de diretrizes de planejamento e projeto de paisagismo e contribuir para a gestão dos ELIUs. Afinal, dados relativos a usos, apropriações, preferências dos usuários e espacializações na estrutura urbana são trazidos à tona para verificação e comparação.

Entre as principais vantagens e contribuições da utilização de multimétodos de pesquisa e o mesmo protocolo, está a possibilidade de utilização em outras categorias tipológicas de ELIU das cidades brasileiras. Entre as limitações, pode-se mencionar que os mesmos foram e estão sendo aplicados entre abril de 2015 e março de 2016, bimestralmente, durante um dia da semana e um fim de semana, somente nos turnos diários da manhã e da tarde. Outra limitação seria a aplicação da pesquisa para a análise de nove ELIUs públicos santa-marienses, sendo seis na categoria de ELIULR e três na categoria de ELIUC. Para maior precisão, os métodos deveriam ser conduzidos durante o ano todo, em diferentes estações do ano, durante quatro dias da semana e quatro fins de semana por mês e, também, durante os três períodos do dia (manhã, tarde e noite).

Até o presente momento, a equipe encarregada do levantamento dos nove ELIUs públicos, constituída por dois professores e trinta acadêmicos (dois destes, bolsistas), iniciou a aplicação dos quatro métodos de pesquisa. Foi possível apreender (apesar das análises de dados cruzados entre si não terem sido efetivadas em sua totalidade) que, nas categorias de ELIU elegidas em Santa Maria, parques, praças, pista multiuso, canteiro central e ciclovia, cumprem função de oferta de atividades ligadas ao lazer e recreação e circulação, todavia nem sempre as suas características físicas levam em consideração os atributos ambientais. Especialmente na categoria ELIULR, a tipologia parque - seja o ltaimbé, o Nonoai ou o Jockey Club - os potenciais naturais (recursos hídricos e mata ciliar) ficam restritos (inclusive delimitados por cercas/telas) às Áreas de Preservação Permanente (APPs), sem possibilidade de acesso, contato e utilização pela comunidade. Em contrapartida, desde 2005, há no município o gravame de Unidades de Conservação (UCs), entre muitas inseridas no espaço intraurbano, porém o tratamento legal segue, em que pese em todo o Brasil, do reconhecimento dessas áreas como de interesse público - mas o efetivo tratamento, projeto paisagístico e inserção na dinâmica da vida pública é inexpressivo.

Outro ponto significativo, a título de apreensão não conclusiva, deve-se ao fato de que os espaços livres intraurbanos precisam ser analisados - pelo meio acadêmico, pelos entes responsáveis pelo planejamento e pela gestão pública do espaço urbano - de modo a compreender quais efeitos interpõem, devido à forma de distribuição, configuração e tipologia, ao tecido urbano e aos usuários. Afinal, há repercussões, apesar da observância da legislação ambiental e urbana, muitas vezes não acompanhadas (ou delegadas) pelo poder público, que os produtores privados do espaço urbano (empreendedores imobiliários, loteadores, associações civis comerciais e industriais) legam à cidade: expansão urbana desconexa à mancha urbana, que atualmente ameaça a 
cadeia de morros; vegetação nativa e nascentes ao norte da área urbana; condomínios horizontais fechados, ao leste, devido à oferta de segurança e proximidade de moradia junto ao campus da Universidade Federal de Santa Maria; eixos de crescimento urbano dependentes de um sistema viário que potencializa os deslocamentos via veículo individual, como no trecho urbano das rodovias RST-287 e RST-509, da avenida Hélvio Basso (ver apêndice) e da Perimetral Dom Ivo Lorscheiter. $\bigcirc$ intuito de eleger para o corrente estudo a categoria ELIU de Circulação, inicialmente demonstra, através das visitas a campo na ciclovia da avenida Hélvio Basso, que a prioridade do desenho urbano dada ao modal veicular (na proporção do espaço destinado ao automóvel, na inexistência de corredor de ônibus e na pouca articulação para a interligação da ciclovia com as imediações) torna esse espaço livre majoritariamente ocupado nos fins de semana para práticas essencialmente esportivas, em detrimento do deslocamento modal alternativo. O contrário pode ser apreendido na pista multiuso da UFSM, inserida num parque setorial, conforme o grupo Quapá-SEL classificou, desenvolvendo funções que se sobrepõem tanto durante a semana, como nos fins de semana. Há circulação interligada à avenida Roraima e imediações desta com o bairro Camobi e práticas de lazer e recreação desenvolvidas por adultos e crianças a caminhar, a andar de bicicleta, patinete, skate, participando de rodas de chimarrão, piqueniques, praticando slackline e yoga nas imediações do referido ELIU.

Apesar disso, percebeu-se, desde as primeiras visitas em campo, que a maioria dos ELIUs apresenta variados problemas: são subutilizados e/ou estão abandonados, não há um princípio compositivo de paisagismo, o que caracteriza os espaços livres públicos pela ausência de vegetação e estruturas físicas, de mobiliários urbanos adequados, pela falta de revestimentos de piso propícios para as diversas práticas sociais e as evidentes depredação e falta de manutenção.

Quanto à localização e espacialização (raios de abrangência/atendimento) dos ELIUs, devem ser promovidos, expandidos e efetivamente implementados pela gestão urbano-ambiental, principalmente no que se refere aos ELIULRs e ELIUCs, pela sua importância para o funcionamento e para a qualidade de vida urbana. Os espaços livres intraurbanos ainda deveriam ser flexíveis e dinâmicos, ao contrário de segmentados ou monofuncionais. Portanto, a elaboração e implantação de projetos de paisagismo qualificados em relação a termos de caracterizações físico-ambiental e social pode embasar-se nos resultados oriundos dos multimétodos.

Almeja-se dar continuidade ao respectivo projeto de pesquisa de forma a expandir a análise para outros ELIULRs e ELIUCs públicos e outras categorias tipológicas de ELIU. Pretende-se, após a coleta em campo, fazer uma síntese crítica e comparativa, através da espacialização das informações físico-ambientais e sociais, em tabelas, gráficos e mapas temáticos. 


\section{REFERÊNCIAS BIBLIOGRÁFICAS}

BABBIE, Earl R. The practice of social research. 7ed. Belmont: The Thomson Wadsworth Corporation, 2007.

CARMONA, Mathew et al. Public Places Urban Spaces: the dimensions of urban design. Oxford: Architectural Press, 2003. 312 p.

.Public Spaces Urban Spaces: the dimensions of urban design. 2 ed. Burlington: Sevier, 2010. 394 p.

; MAGALHÃES, Claudio de. Public Space: the management dimension. New York: Routledge, 2008. 232 p.

CRESWELL, John. Research design: qualitative, quantitative, and mixed methods approaches. 3 ed. New Delhi: SAGE Publications Inc, 2009. 273 p.

DI MARCO, Alba I. et al. El espacio público desde una visión paisajística: bases de interpretación para Córdoba ciudad. Córdoba: Universidad Nacional de Córdoba, Faculdade de Arquitectura, Urbanismo y Diseno, 2009. 304 p.

ESTBERG, Kristin, G. Qualitative methods in social research. New York: University of Massachusetts - Lowell, 2002.

GEHL, Jan. Lively, attractive and safety cities - but how? In: HASS, T. New urbanism and beyond: designing cities for the future. New York: Rizzoli International, 2008, p. 106-108.

Cities for people. Washington: Island Press, 2010. 269 p.

Life between buildings: using public space.Washington: Island Press, 2011. 207 p.

Cidade para pessoas. 2 ed. São Paulo: Perspectiva, 2014. 280 p.

; SVARRE, Birgitte. How to study public life. Washington: Island Press, 2013. 200 p.

GROAT, Linda; WANG, David. Architectural research methods. 2 ed. New York: John Wiley \& Sons Inc., 2002. $498 \mathrm{p}$.

LEEDY, Paul D.; ORMROD, Jeanne E. Practical research: planning and design. 8 ed. New Jersey: Pearson Education Inc, 2005

LIMBERGER, Lucienne R. L.; PIPPI, Luis Guilherme A.; LAZAROTTO, Gerusa. Praças urbanas - o caso da praça João Menna Barreto - Santa Maria - RS - Brasil: procedimentos metodológicos projetuais paisagísticos aplicados à disciplina de Paisagismo II. Paisagem e Ambiente: ensaios, São Paulo: FAUUSP, n. 23, 2007, p. 145-157.

Paisagismo brasileiro na virada do século: 1990-2010. São Paulo: Edusp, 2012. 344 p.

et al. Considerações Preliminares Sobre o Sistema de Espaços Livres e a Constituição da Esfera Pública Contemporânea no Brasil. In: Sistema de Espaços Livres: o cotidiano, apropriação e ausências. Rio de Janeiro: Universidade Federal do Rio de Janeiro, Faculdade de Arquitetura e Urbanismo, Pós-Graduação em Urbanismo, Coleção PROARQ, 2009.

MAGNOLI, Miranda Martinelli. Espaço Livre - objeto de trabalho. Open Spaces. Paisagem e Ambiente: ensaios. São Paulo: FAUUSP, n. 21, 2006a, p. 175-198.

. Em busca de "outros" Espaços Livres de Edificação. Paisagem e Ambiente: ensaios. São Paulo: FAUUSP, n. 21, 2006b, p. 141-174.

MARCELLINO, Nelson Carvalho (Org.). Políticas públicas setoriais de lazer: o papel das prefeituras. Campinas: Autores Associados, 1996. 134 p.

OKAMOTO, Jun. Percepção ambiental e comportamento: visão holística da percepção ambiental na arquitetura e na comunicação. São Paulo: Mackenzie, 2002. 264 p.

PATTON, Michael Q. Qualitative evaluation and research methods. 3 ed. Thousand Oaks: Sage Publications Inc, 1990, p. 64-91.

PELLEGRIN, Ana de. O espaço de lazer na cidade e a administração municipal. In: MARCELLINO, Nelson Carvalho (Org.). Políticas públicas setoriais de lazer: o papel das prefeituras. Campinas: Autores Associados, 1996, p. 31-38.

PIPPI, Luis Guilherme A. et al. Sistema de espaços livres contemporâneos na cidade de médio porte de Santa MariaRS. Paisagem e Ambiente: ensaios. São Paulo: FAUUSP, n. 26, 2009, p. 89-196.

et al. A dinâmica dos espaços livres intraurbanos da cidade de Santa Maria-RS. Paisagem e Ambiente: ensaios. São Paulo: FAUUSP, n. 29, 2011 , p. 189-226. 
Social network interaction and behaviors on recreational greenways and their role in enhancing greenway potential. Final Dissertation, degree of Doctor of Philosophy (Landscape Architecture) in Design, North Carolina State University, Raleigh, NC, EUA, 2014. 846 p.

TRINDADE, Larissa C. O papel da vegetação e das florestas nas áreas urbanas. Paisagem e Ambiente: ensaios. São Paulo: FAUUSP, n. 31, 2013, p. 81-96.

PROJETC FOR PUBLIC SPACES (PPS). How to turn a place around: handbook for creating successful public spaces. 2 ed. New York: Project for Public Spaces Inc., 2000.

PUNCH, Keith F. Introduction to social research: quantitative \& qualitative approaches. California: SAGE Publications Ltd, 2000. 408 p.

SOMMER, Robert; SOMMER, Barbara. A practical guide to behavior research: tools and techniques. 5 ed. New York: Oxford University Press, 2002. 264 p.

TURNER, Tom. Greenways, Blueways, Skyways and Other Ways to a Better London. Landscape and Urban Planning. Dartford: School of Architecture and Landscape, University of Greenwich volume 33, Issues 1-3, 1995, p. 269-282.

YIN, Robert K. Case study research: design and methods. 3 ed. Thousand Oaks: SAGE Publications, 2003. 179 p.

Case study research: design and methods. 5 ed. Los Angeles: SAGE Publications, 2009. 282 p.

ZAMANI, Zahra; MLEE, Jong S.; PIPPI, Luis Guilherme A. Exploring behaviors and perceptions of users in a neighborhood park. Saarbrucken: LAP Lambert Academic Publishing, 2014. 69 p.

ZEIZEL, John. Inquiry by design: environment/behavior/neuroscience in architecture, interiors, landscape and planning. New York: W.W. Norton \& Company, 2006. 416 p. 
Utilização De Multimétodos de Caracterização e Análise da Paisagem

e dos Espaços Livres Intraurbanos De Santa Maria-RS

\section{APÊNDICE}

PESQUISA QUALITATIVA DE INTERAÇAO COM O USUARIO DO ESPAÇO PÚBLICO

(Metodo 1: Questionário Qualitativo)

LOCAL:

DATA:

PESQUISADOR

HORARIO/TEMPO DE APULACĀOA:

PERIODO DO CLA: manhà - tarde - noite

TEMPERATURA: mínima míxima

CONDIÇAO SOLARE ensolarado - nublado - parcialmente ensolarado-parcialmente nublado - chuvoso

QUESIIONAMENTOS: CONYERSA COM OS TRANSEUNTES

1. Defina este lugar com très palavras:

2. Aponte aspectos positivos deste lugar:

3. Aponte aspectos negativos deste lugar:

4. Qual sentimento este espaço te provoca

5. Qual/ quais atividade voce faz neste lugar?

6. Qual/ quais atividades vocè gostaria de fazer neste lugan?

7. Qual dos ambientes deste lugar vocè gosta mais? Por que?

OBSERVACOOES 


\section{PESQUISA QUANTITATIVA DE INTERACAO COM O USUAFIO}

(Método 2: Survey Quantitativo)

LOCAL:

MES:

( ) dia de semana ( ) final de semana

PESQUISADOR:

HORARIO/TEMPODE APLICAC,AO

PEFIODO DOCU: manhà-tarde-noite TEMPERATURA: minima máxima

CONDIC A̧AO SOLARE Cnsolarado - nublado - parcialmente ensolarado - parcialmente nublado - chuvoso

1. Populaç̇o | Género

() Feminino ( ) Masculino

2. Populaça | Idade

) Crianxas ( 0 - 12 anos) (1) Adultos (18 - 65 anos)

() Adiolescentes (13-17 anos) ( ) idosos (> 65 anos)

3.E morador de Santa M aria/RS?

( ) $\mathrm{sim}$

( ) Nĩo

4. Por qual razåo vocè utiliza o espaço público? (voce pode escolher meis de uma alternativa)

() Atividades fisicas

) Interaça social

) Estar com a famik.

J Laços de arnizade

J Interagir com vizinhos do bairro

) Interagir com pessoas de bairros vizinhos

) Proximidade de aireas comerciais

) Proximidade de lugares historico

Presenca de pracinha

J Presença de academia ao ar livre

) Presenca de bancos e estares

) Curtiçao/ Prazer

JCriatividade

J Relaxar/ Meditar

Turismo

) Eventos sociais

( Conhecimento

( ) Estimulo

( ) Observaçio da fauna

( ) Observar paisagens

( ) Observar pessoas

( ) Introspecsalo/ Espiritualidade

( ) Programas Fdixacionais

( ) Programas/Eventos Socias

( Programes Comunitários

( ) Apreciaça/ /nteraçåo com a natureza

( Transporte/ Mobilidade alternativa

( ) Proximidade da minha residencia

( ) Presença de bons servicos e infraestrutura

( ) Fuga das pressöes sociais/ pessoais

( ) Caminhando/Erincando com animais domésticos

) solitude

( ) Outros

5. Com que frequência utiliza este espaço público?

1 - 3 weres por semana () Mais de 3 vezes ao mès

6. Quando vocè geralmente usa este espaço público?

$\begin{array}{lll}\text { () Finais de semana } & \text { ( ) Eventos especiais } & \text { ( ) Ferias } \\ \text { j) Dias de semana } & \text { () Feriados }\end{array}$

7. Qual horário vocể geralmente usa este espaço público?

)6-11h (manha) ( ) $17 \cdot 20 \mathrm{~h}$ (entardecer)

) $12-16 \mathrm{~h}$ (tarde) ( ) Depois das $21 \mathrm{~h}$ (noite)

8. Ouento tempo vocè fica neste espaço público?

) Menos de 10min () 31min - 1h () 2-3h

j10-30min ( ) 1-2h () Mais de 3 h

9. Vocé utiliza este espaç๐ público com: (vocé pode escolher mais de uma alternativa)

$\begin{array}{lll}\text { ) Sozinho } & \text { ( ) Com amigo } & \text { ( ) Com membros/ associaç } \\ \text { jCom a familia } & \text { ( ) Com grupo de amigos } & \text { ( ) Com estranhos } \\ \text { jCom crianças } & \text { ( ) Com grupos religiosos } & \text { ( ) Com animais domésticos } \\ \text { jCom o cônjuge } & \text { ( ) Com colegas } & \text { ( )utros }\end{array}$

Com o cóniuge ( Com colegas

) Ninguém (1) 2 pessoas

11 pessoa (13 a 4 pessoas

( ) Mais de 4 pessoas 
Utilização De Multimétodos de Caracterização e Análise da Paisagem

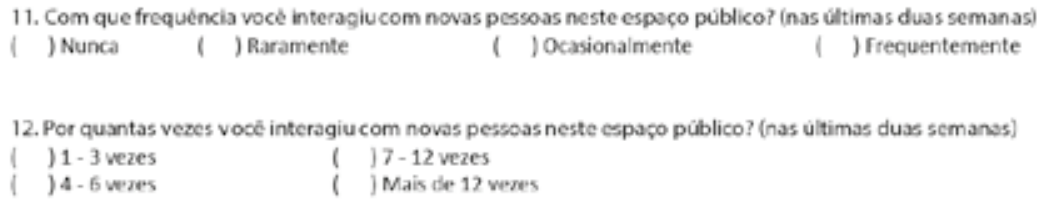

13. Se na perqunta anterior, vocé marcou que interage com novas pessoas neste espaço público, por quanto tempo? (nas últimas duas semanas)

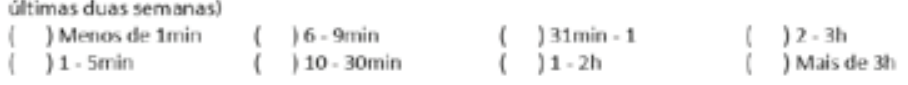

14. Com quantas novas pessoas você interagiu neste espoço público? (nas últimas dues semanas

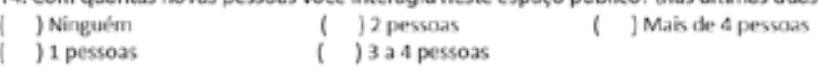
15. Qual tico de interaça com as novas pessoas neste espaço público? Inas últimas duas semanas
) Sortit/abanat
Cumprimentar um estranho sem interromper a atividade
jencontrar/ Fazer atisidodes junto com estranhos
16. O qủo importante é para você sociabilizar com novas pessoas neste espaço público?
( ) Nào importante ( ) Importante ( ) Muito importante
17. Com que frequéncia vocè interagiu com pessoas conhecidas neste espaço público? inas últimas duas semanas:
Nunca ( ) Raramente ( ) Ocasionalmente ( ) Fresuentemente

18. Por quantas vezes voce interagiu com pesscas conhecidas neste espaço público? (nas últimas duas semanas)
) 1 - 3 vezes

$\begin{array}{ll}\text { (1-3 vezes } & \text { ( ) } 7 \text {-12 vezes } \\ \text { (1) } 4 \text { veres } & \text { (Mais de } 12 \text { veres }\end{array}$

19. Se na perqunta anterior, vocé marcou que interage com pessoas conhecidas neste espaço público, por quanto tempo? (nas últimas duas semanas)
) Menos de $1 \mathrm{~min}$
(16.9min
() $31 \mathrm{~min}$ -
) $2 \cdot 3 \mathrm{~h}$
) 1 - 5 min
( $10-30 \mathrm{~min}$
( ) $1-2 \mathrm{~h}$
() Mais de 3h

20. Com quantas pessoas conhecidas você interagiuneste espaço público? (nas úl timas duas semanas)

$\begin{array}{lll}\text { () Ninguém } & (12 \text { pessoas } & (\text { ) Mais de } 4 \text { pessoas } \\ \text { (1) pessoa } & (\text { ) } 3 \text { a } 4 \text { pessoas }\end{array}$

21. Qual o seu tipo de interaçajo com pessoas desconhecidos e/ou conhecidas neste espaço publico? (nas últimas duas semanas)

( ) Sorrir/abanar

jCumprimentar um familiar sem interromper a atividade

Cumprimentar um amigo sem interromper a atividace

) Cumprimentar um estranho sem interromger a atividade

) Encontro casual com familiares

jencontro casual com amigos

jencontro casual com estranhos

Fncontrar/ Fazer atividades junto com familiares

) Encontrar/ Fazer athidades junto com amigos

jencontrar/ Fazer atisidades junto com estranthos

22. O quj̃o importante é para você sociablizar com pessoas conhecidas neste espaço público?

() N3o importante ( ) Importante ( ) Muito importante

OBSERVACOES: 
Luis Guilherme Aita Pippi, Letícia de Castro Gabriel, Renata Michelon Cocco,

Letícia de Fátima Durlo Coutinho, Henrique Schwingel e Marcos Guterres Giovelli

\section{PESOUISA QUANTITATIVA SEM INTERACAAO COM O USUARIO}

(Método 3: Observação Direta e Mapas Comportamentais)

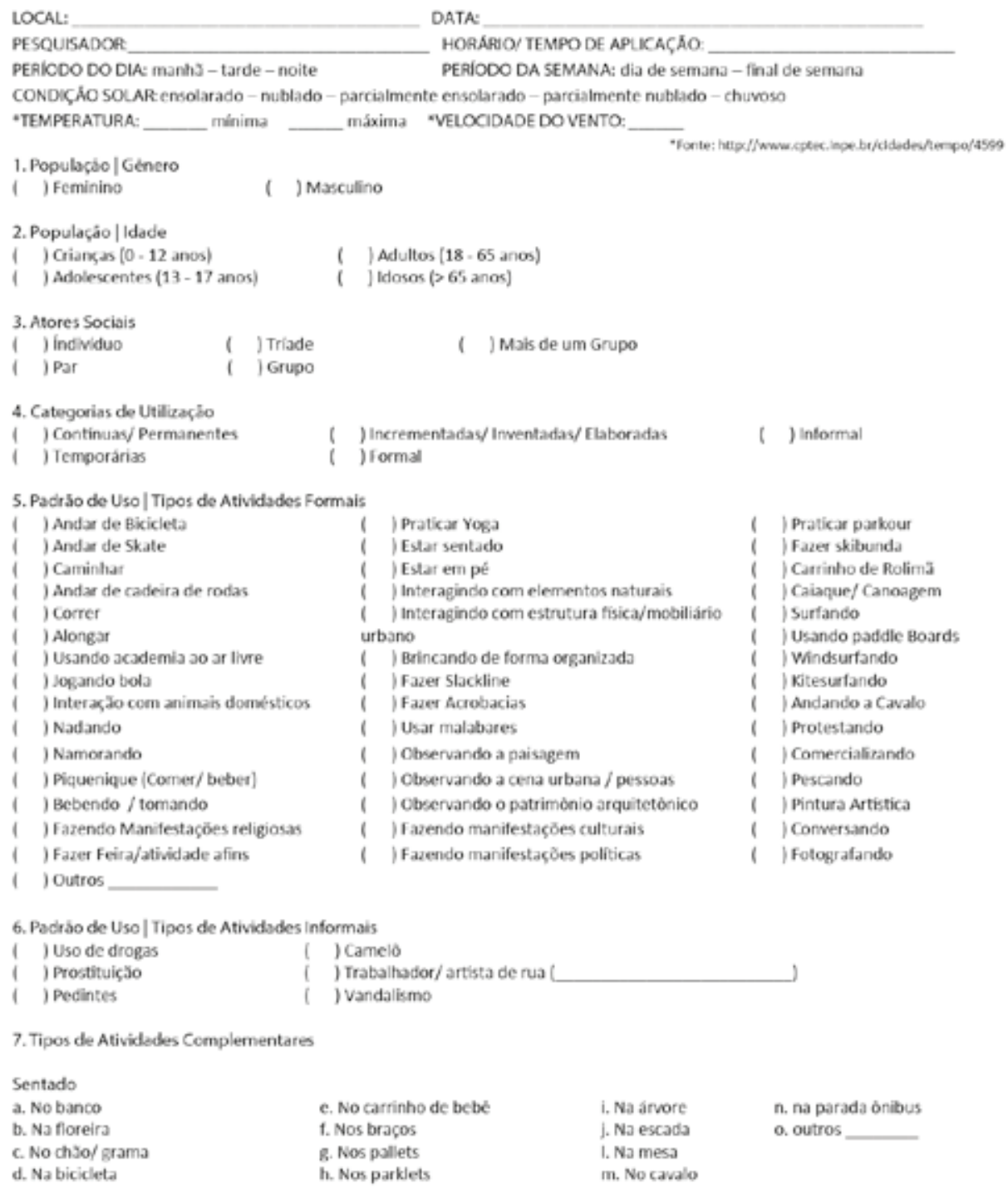


Utilização De Multimétodos de Caracterização e Análise da Paisagem

e dos Espaços Livres Intraurbanos De Santa Maria-RS

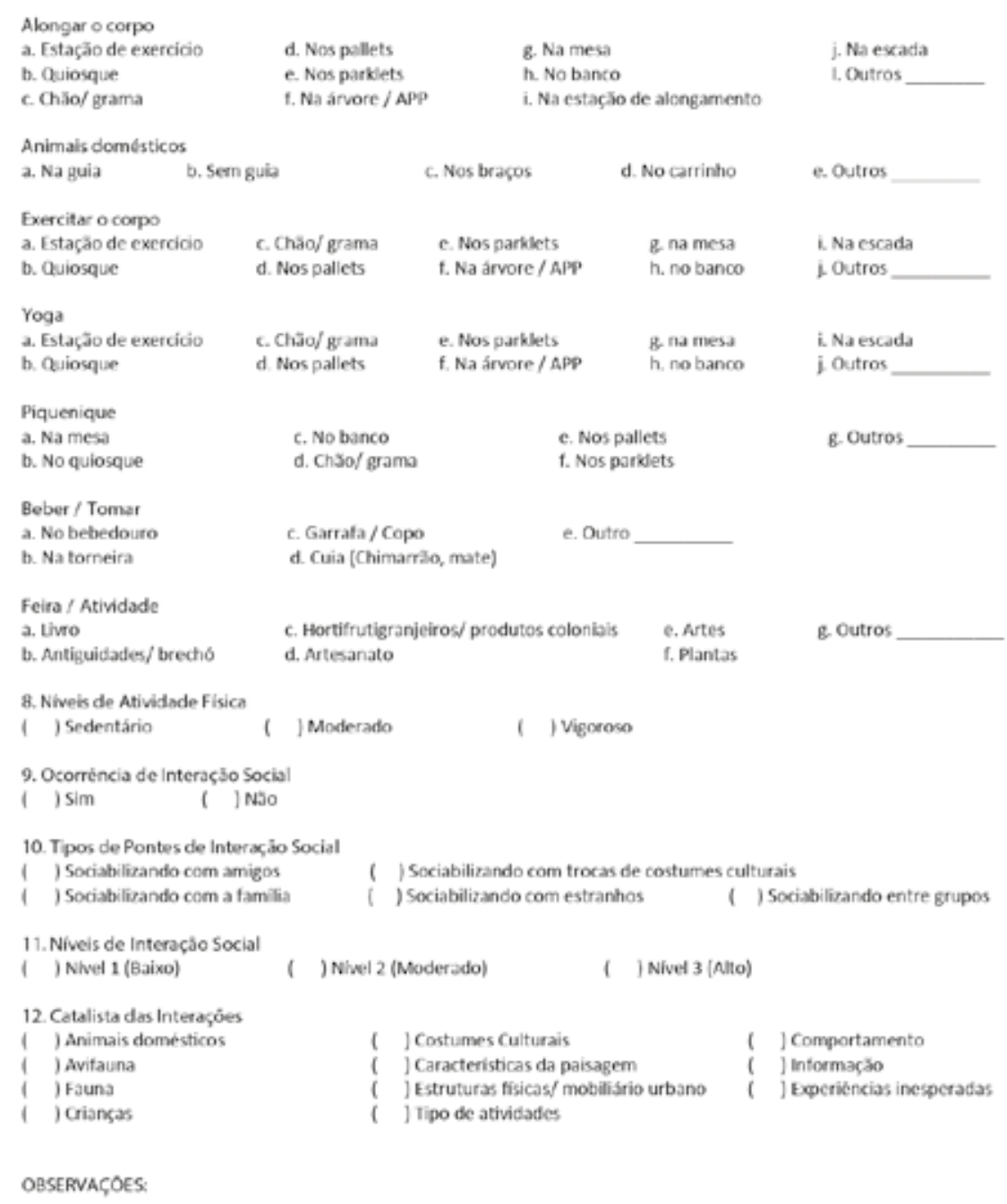




\section{PESQUISA QUANTITATIVA DE CARACTERIZAÇAOO DOS ESPAÇOS LIVRES SEM INTERAÇÃO COM O USUARIO}

(Metodo 4 Caracterizaçáo dos Espacos Livres Intraurbanos Públicos)

LOCAL:

DATA

PESQUISADOR:

HCRÁRIO/TEMPO DE APLICAÇÁ:

PEPIODO COCLA: manhț-tarde-noite TEMPERATURA: mínima míxima

CONDIC ÁO SOLARE cnsolarado - nublado - parcialmente ensolarado - parcialmente nublado - chuvoso

7ONEAMENTO DA ZONA DO PDDUA (FOR TRFCHOS/ QUADRAS RUAS)- ANAL ISAR BAIRRO/ZONA PDDUA/ ESPACOS IIVRES

1. Usos MAIS SIGNIFICATINOS E SIMBÓLICOS - RECORTE

() Público ( ) Privado

2. RAIOS DEATENDIMENTO DOS ESPAÇOS LINRES

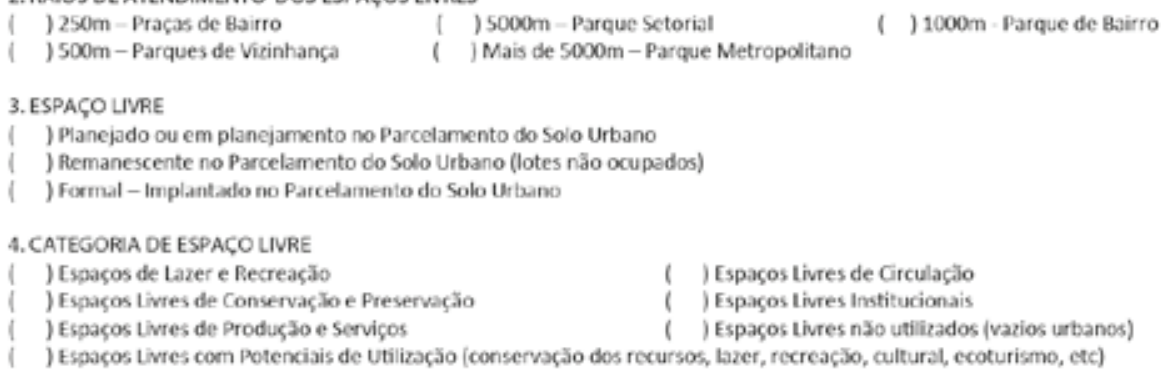

CARACTERIZAÇAO DOS CONDICIONANTESFISICOAMBIENTAIS DOS ESPAÇOS LIVRES - ANALISE DE SUPORTE FISICO

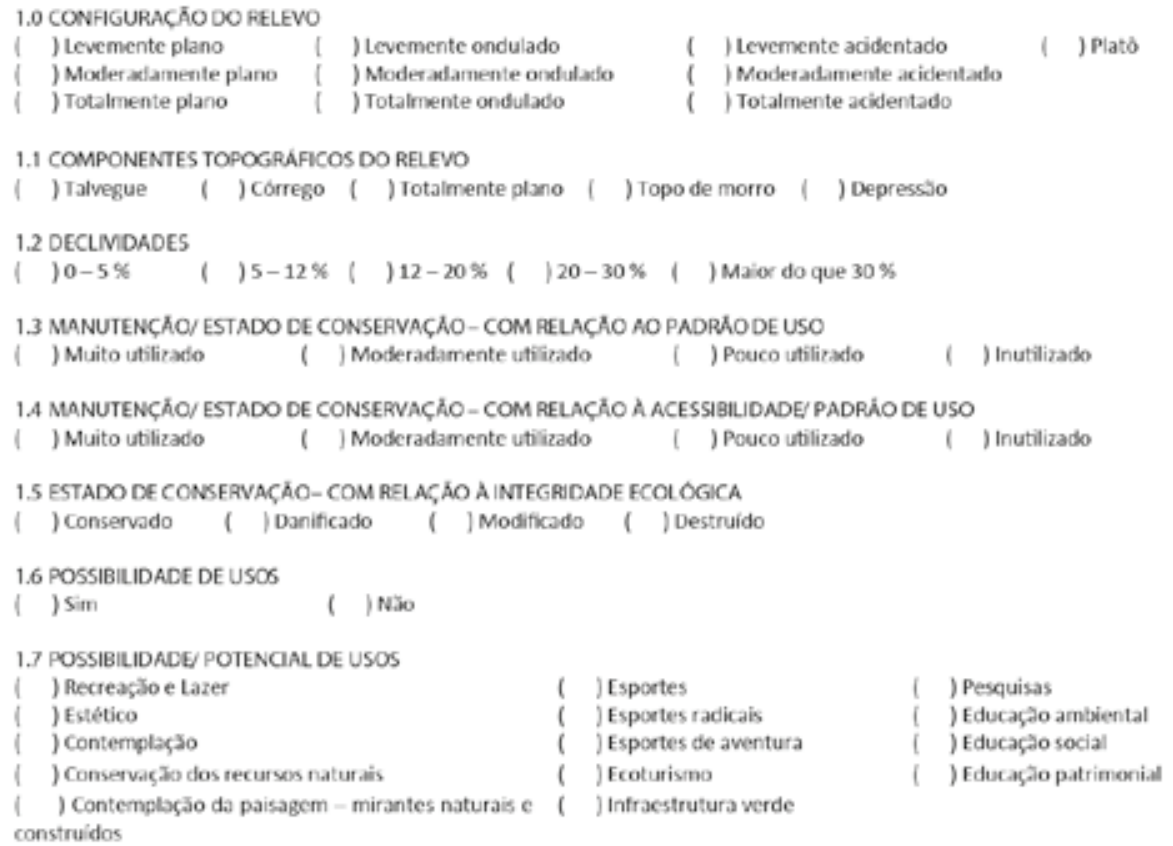




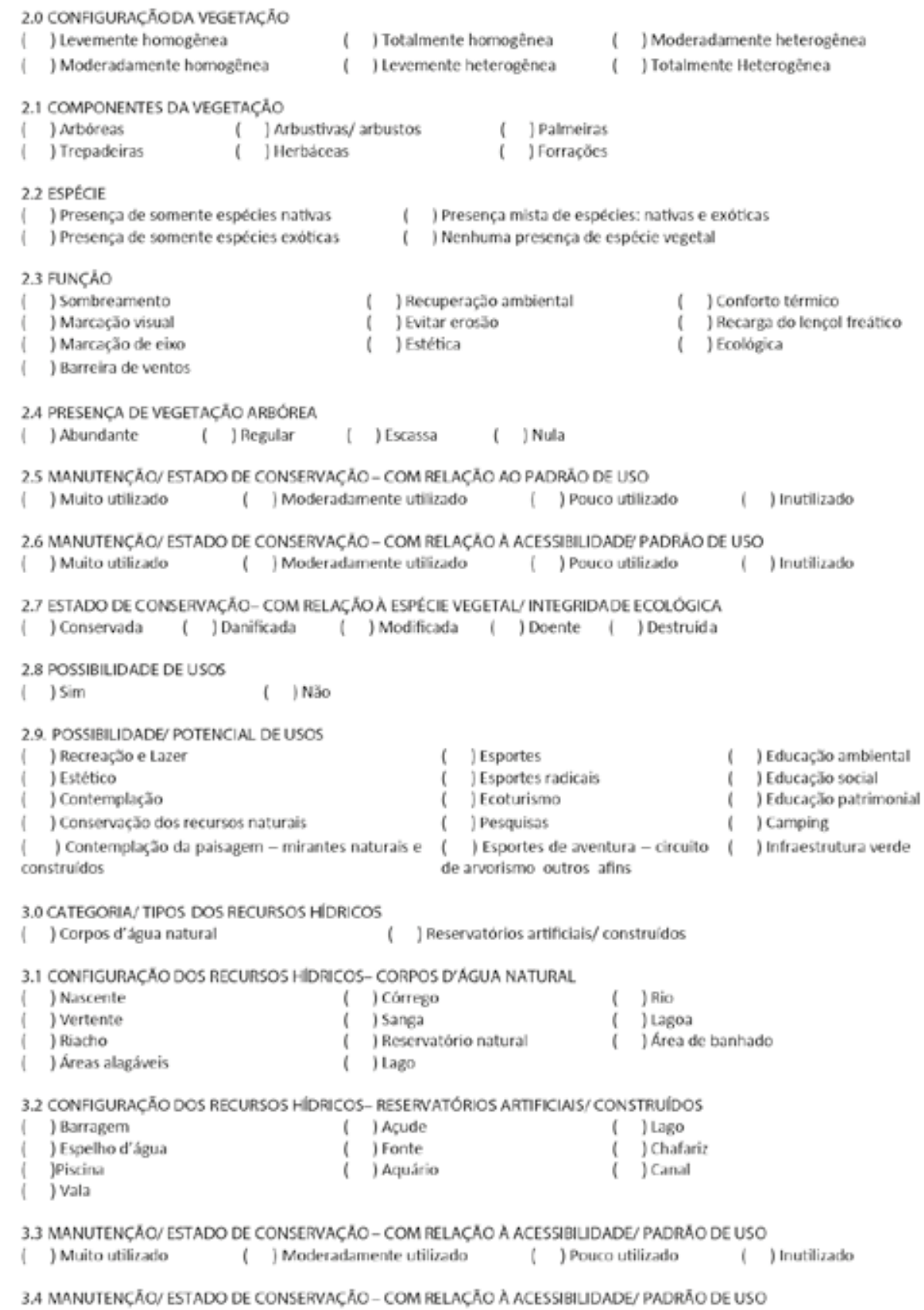


Luis Guilherme Aita Pippi, Letícia de Castro Gabriel, Renata Michelon Cocco,

Letícia de Fátima Durlo Coutinho, Henrique Schwingel e Marcos Guterres Giovelli

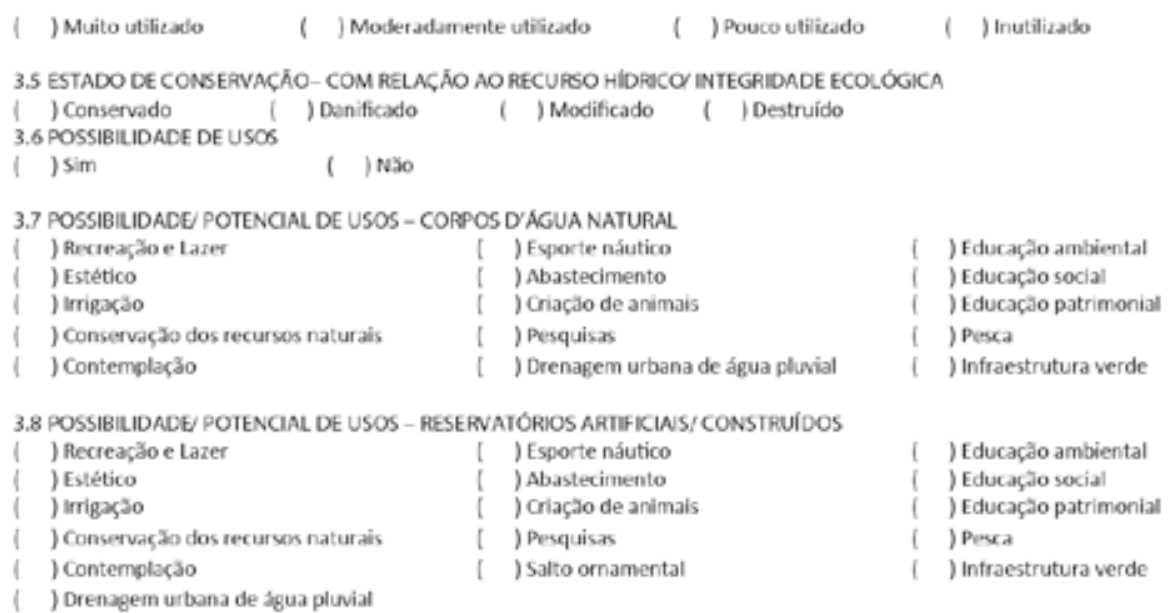

ANALISE E DESCRIÇAO DO ESPACCO UVRE INTRAUURANO - TIPO DE ATIVIDADES NO ESPAÇO LIVRE

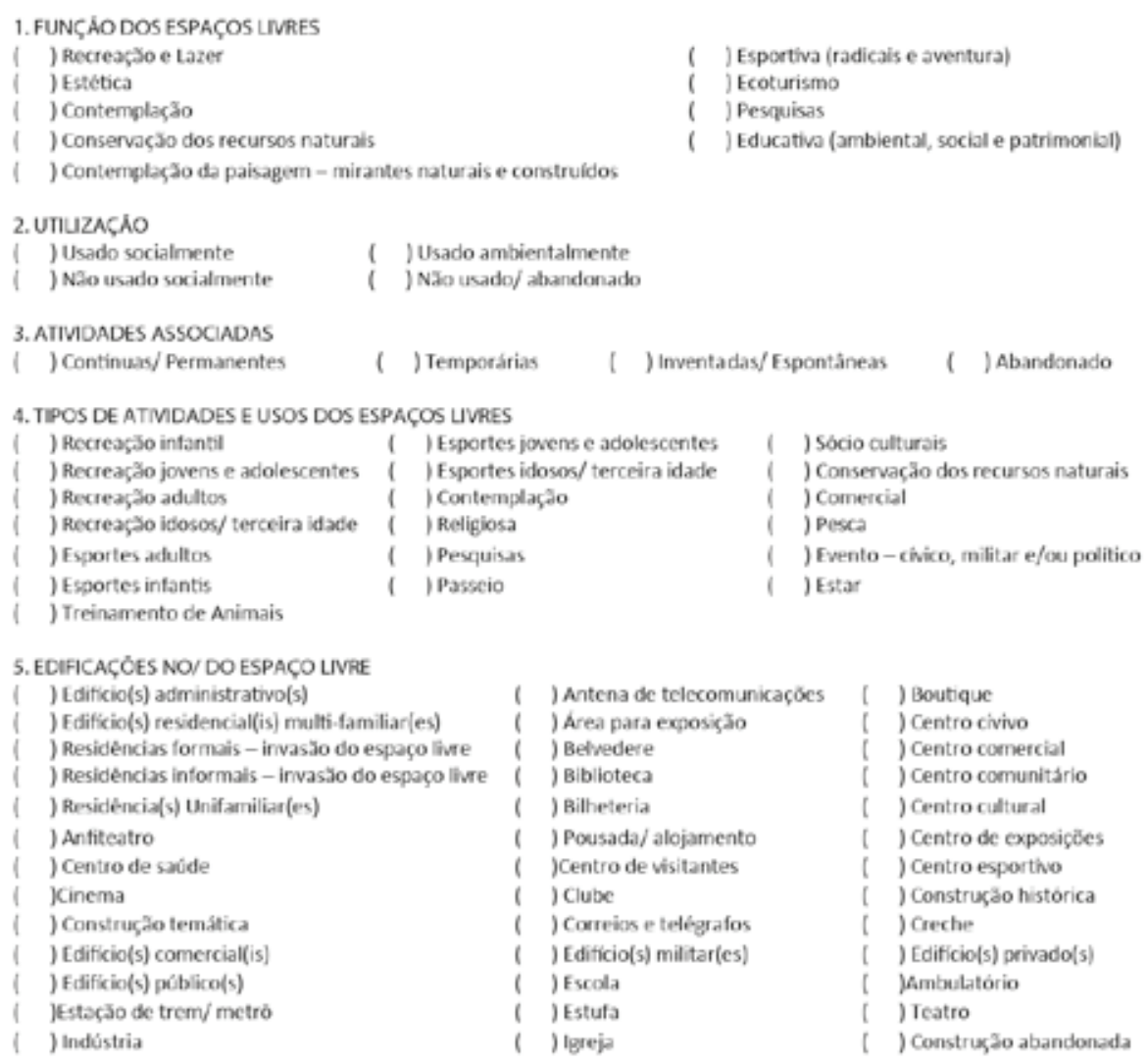




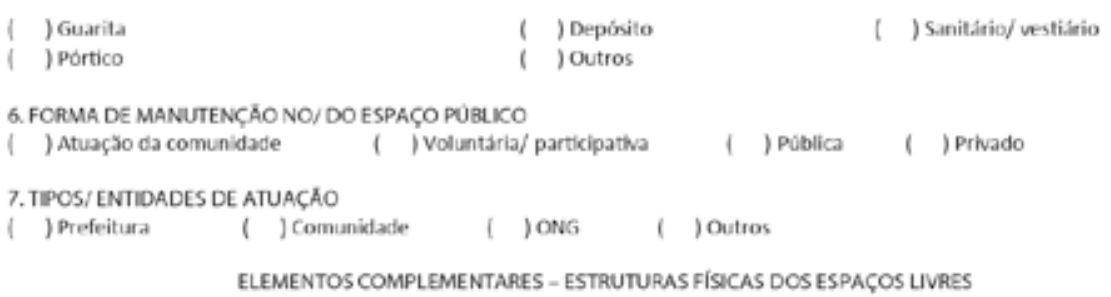

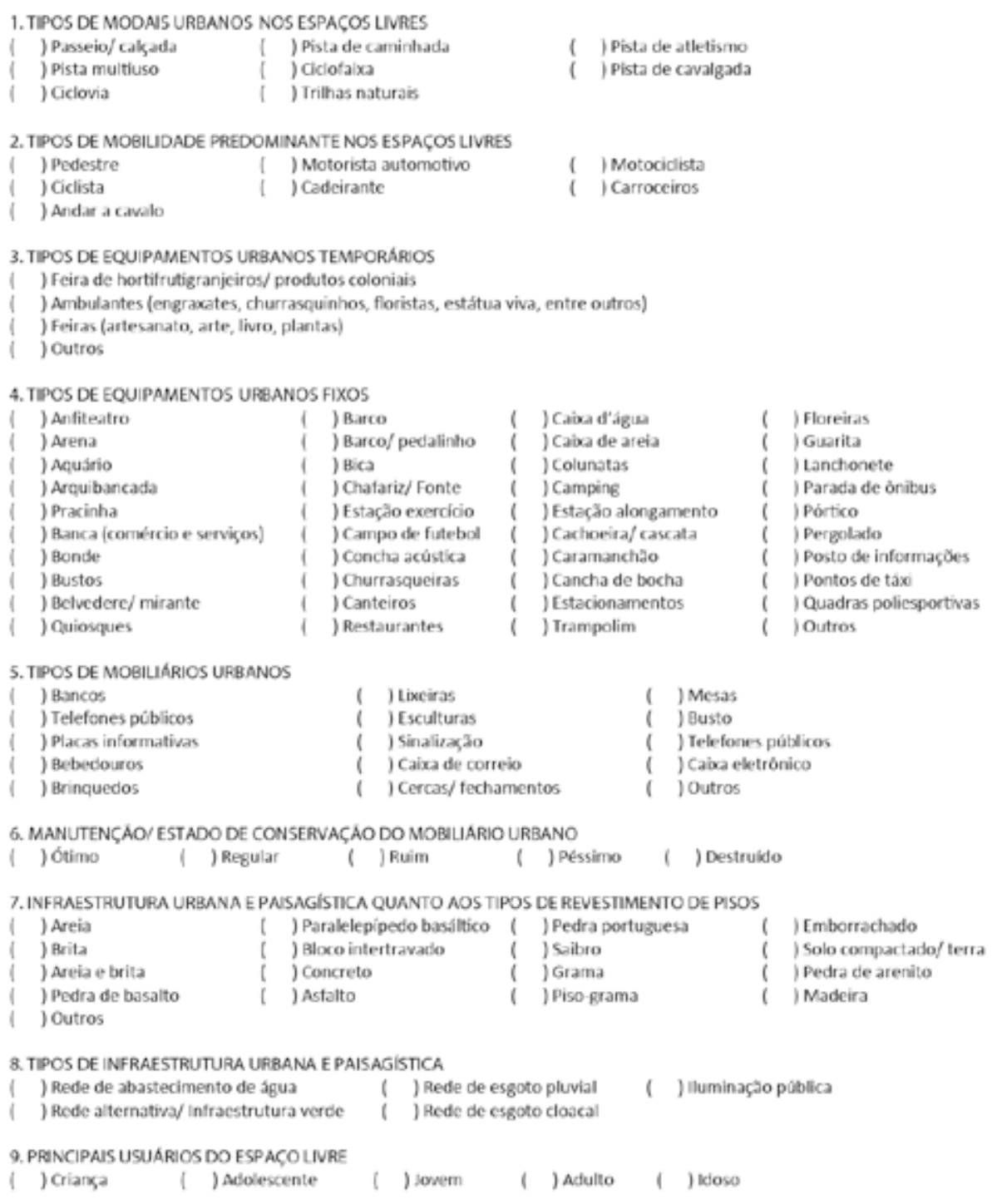


Luis Guilherme Aita Pippi, Letícia de Castro Gabriel, Renata Michelon Cocco,

Letícia de Fátima Durlo Coutinho, Henrique Schwingel e Marcos Guterres Giovelli

10. EXISTE ALGUMA RELAÇĀO SOCIAL COM A VIDA SILVESTRE

( ) Sim ( ) N3O

11. EXISTE ALGUMA REL AÇÃO SOCIAL COM ANIMAIS DOMÉSTICOS

( ) Sim ( ) N3O

12. SEGURANÇA

( ) Policiamento permanente ( ) Policiamento esporádico $($ ) Segurança privativa

13. VISIBILIDADE

() Boa visibilidade entre diferentes pontos ( ) Pouca visibilidade entre diferentes pontos

MÁSCARA DOS ESPAÇOS LIVRES- ANÁLISE DO TECIDO URBANO NO ENTORNO IMEDIATO DOS ESPAÇOS LIVRES DE SANTA MARIA PADRÓES MORFOLÓGICOS DO TECIDO URBANO NO ENTORNO LIMITROFE AO ESPAÇO LIVRE

1. VERTICALIZAÇÃO (MAPA)

( ) Área urbana horizontal

( ) Área urbana verticalizada

( ) Área urbana semi-verticalizada

( ) Área urbana adensada

( ) Area urbana esparsa

2. ALTURAS EM PAVIMENTOS (MAPA)

( ) 1 a 2 (amarelo)

( ) 6 a 8 (vermelho)

( ) 9 a 16 (marrom claro)

( ) Mais que 16 (marrom escuro)

( ) 3 a 5 (laranja)

EDIFICIOS (MAPA)

() Muito contiguos/contínuos ( ) Medianamente contiguos/continuos ( ) Muito descontiguos/descontínuos

4. FUNÇÓES E USOS URBANOS

( ) Residencial

( ) Institucional

( ) Comercial/ prestaçåo de serviços ( ) Especial

( ) Misto ( ) Industrial

5. VIAS LIMITROFES AO ESPAÇO LIVRE
( ) Locais
( ) Coletoras
( ) Arteriais
( ) Expressas

6. REVESTIMENTO DE PISO DAS RUAS AO ENTORNO DO ESPAÇO LIVRE

( ) Pavimentada permeável ( ) Pavimentada impermeável

() Nio pavimentada ( ) Misto-pavimentada e nào pavimentada

7. FLUXO DO ENTORNO

( ) Automóvel/ veiculo leve ( ) Bicicleta () Tração animal

( ) Ônibus coletivo ( ) Carga e descarga/veiculo pesado ( ) Industrial

8. ACESSO AO ESPAC OLIVRE

$($ ) Público ( ) Semi-público $($ ) Privado

9. ACESSIBILIDADE

( ) Presença de faixas de segurança ( ) Presença de rebaixamentos de guias/ vias

( ) Presença de semáforos para automóveis ( ) Presença de passarelas/ rampas para pedestres

( ) Presença de sinalização ( ) Transporte público (trem, metrô, ônibus)

( ) Acesso a PNE ( ) Iransporte privado (automóvel, motocicleta, carroça)

( ) Pista de caminhada/ peatonal ( ) Passeio público

( ) Pista de ciclismo ( ) Rua

OBSERVAÇŌES: 
Tabela 4 Ambiência da Praça Saldanha Marinho

\begin{tabular}{l|l}
\hline \multicolumn{1}{c|}{ ELIULR } & \multicolumn{1}{c}{ Praça Saldanha Marinho } \\
\hline Caracterização & $\begin{array}{l}\text { Praça mais antiga e emblemática da cidade, que sofreu inúmeras } \\
\text { transformações em suas linhas projetuais paisagísticas, à qual foram } \\
\text { incorporadas novos usos e novas estruturas físicas, como área livre para } \\
\text { passagem de veículos e pedestres, floreiras, ampliação da fonte, anfiteatro } \\
\text { e sanitários. Entre os elementos originais conservados estão o chafariz e o } \\
\text { coreto. Entorno comercial com algumas edificações históricas. }\end{array}$ \\
\hline Conflitos & $\begin{array}{l}\text { Paisagismo pouco elaborado no que se refere ao layout do mobiliário } \\
\text { urbano, revestimentos de piso e vegetação. Sanitários apresentam } \\
\text { precariedade de conservação. Demarcação e apropriação privada parcial do } \\
\text { espaço público pelo Teatro Municipal da cidade. }\end{array}$ \\
\hline Uela centralidade e pelo valor histórico e patrimonial, destaca-se como \\
grande potencial articulador social, cultural, turístico e comercial.
\end{tabular}

Fonte: Arquivo do grupo Quapá-SEL II, núcleo Santa Maria, 2015. 


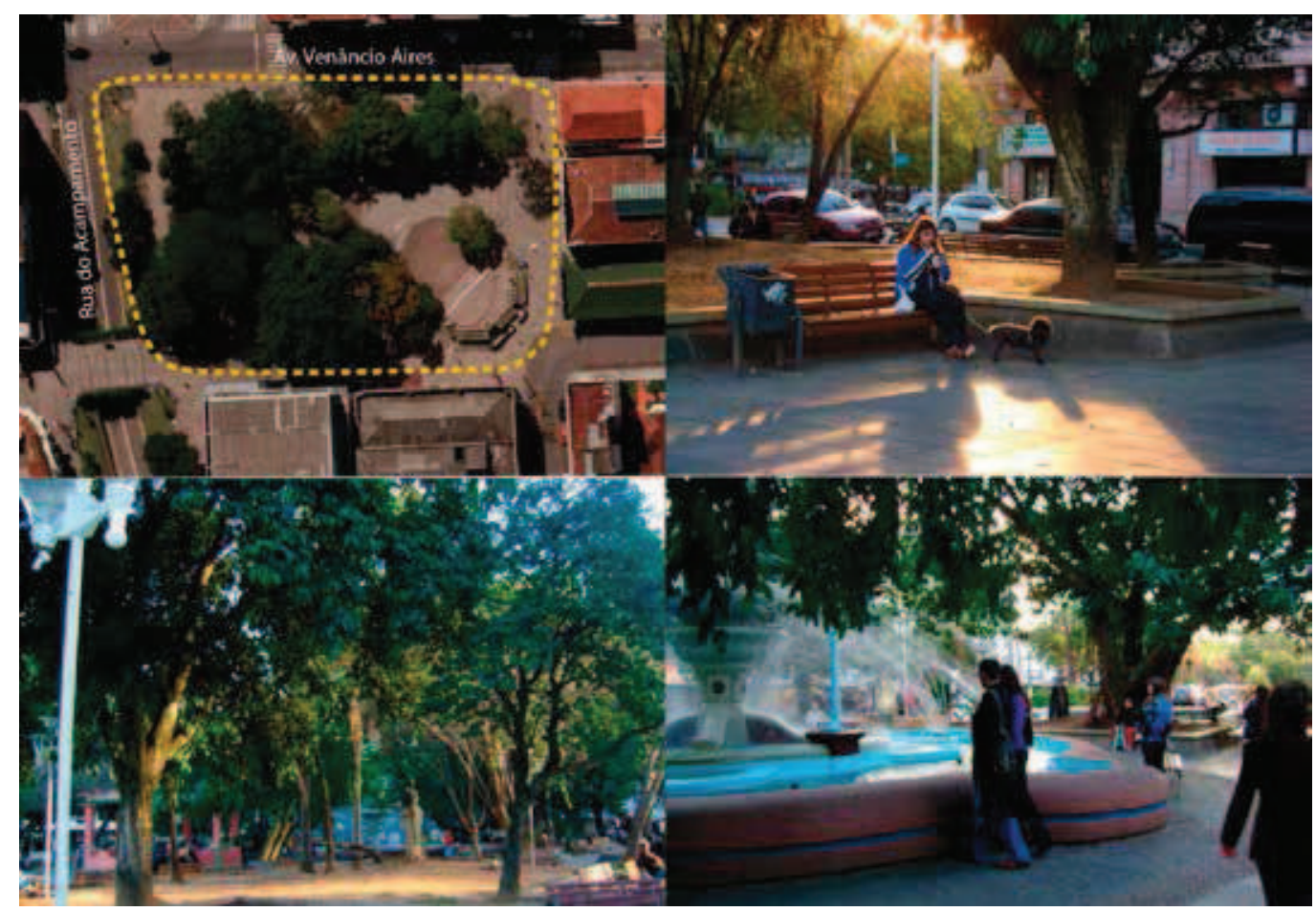

Figura 5 ELIULR - Praça Saldanha Marinho.

Fonte: Arquivo do grupo Quapá-SEL II, núcleo Santa Maria, 2015.

Tabela 5 Ambiência da praça Saturnino de Brito

\begin{tabular}{l|l}
\hline \multicolumn{1}{c|}{ ELIULR } & \multicolumn{1}{c}{ Praça Saturnino de Brito } \\
\hline Caracterização & $\begin{array}{l}\text { Praça de importância histórica para a qual foi previsto um mercado público } \\
\text { não concretizado. Relacionada diretamente ao plano de embelezamen- } \\
\text { to, higienização e sanitarismo elaborado no início do século XX. Contém } \\
\text { características ecléticas (traçado dos canteiros) e modernistas (laje jardim, } \\
\text { playground e chafariz). }\end{array}$ \\
\hline Conflitos & $\begin{array}{l}\text { Seu uso é conflituoso pela recorrente ocupação por parte de estudantes du- } \\
\text { rante trotes universitários, ocasionando acúmulo de lixo e depredação da es- } \\
\text { trutura física do local. Possui mobiliário urbano desqualificado e vegetação } \\
\text { arbustiva sem poda/condução, o que compromete a visibilidade e a segu- } \\
\text { rança dos usuários. Ocorre verticalização do entorno imediato, comprome- } \\
\text { tendo a insolação e ventilação adequadas à praça. Há um playground para } \\
\text { uso recreativo infantil e um chafariz - ambos em estado de degradação. }\end{array}$ \\
\hline Potencialidades & $\begin{array}{l}\text { Localizada em área de comércio, é um espaço de respiro urbano e contribui } \\
\text { no caráter da centralidade (por ter fácil acessibilidade), da mesma forma } \\
\text { que poderia incentivar o uso e a permanência de diferentes faixas etárias. }\end{array}$ \\
\hline Usos Públicos & $\begin{array}{l}\text { Taxistas, feira temporária de hortifrutigranjeiros, uso intenso por jovens devi- } \\
\text { do à presença de bares no entorno. }\end{array}$ \\
\hline
\end{tabular}

Fonte: Arquivo do grupo Quapá-SEL II, núcleo Santa Maria, 2015. 


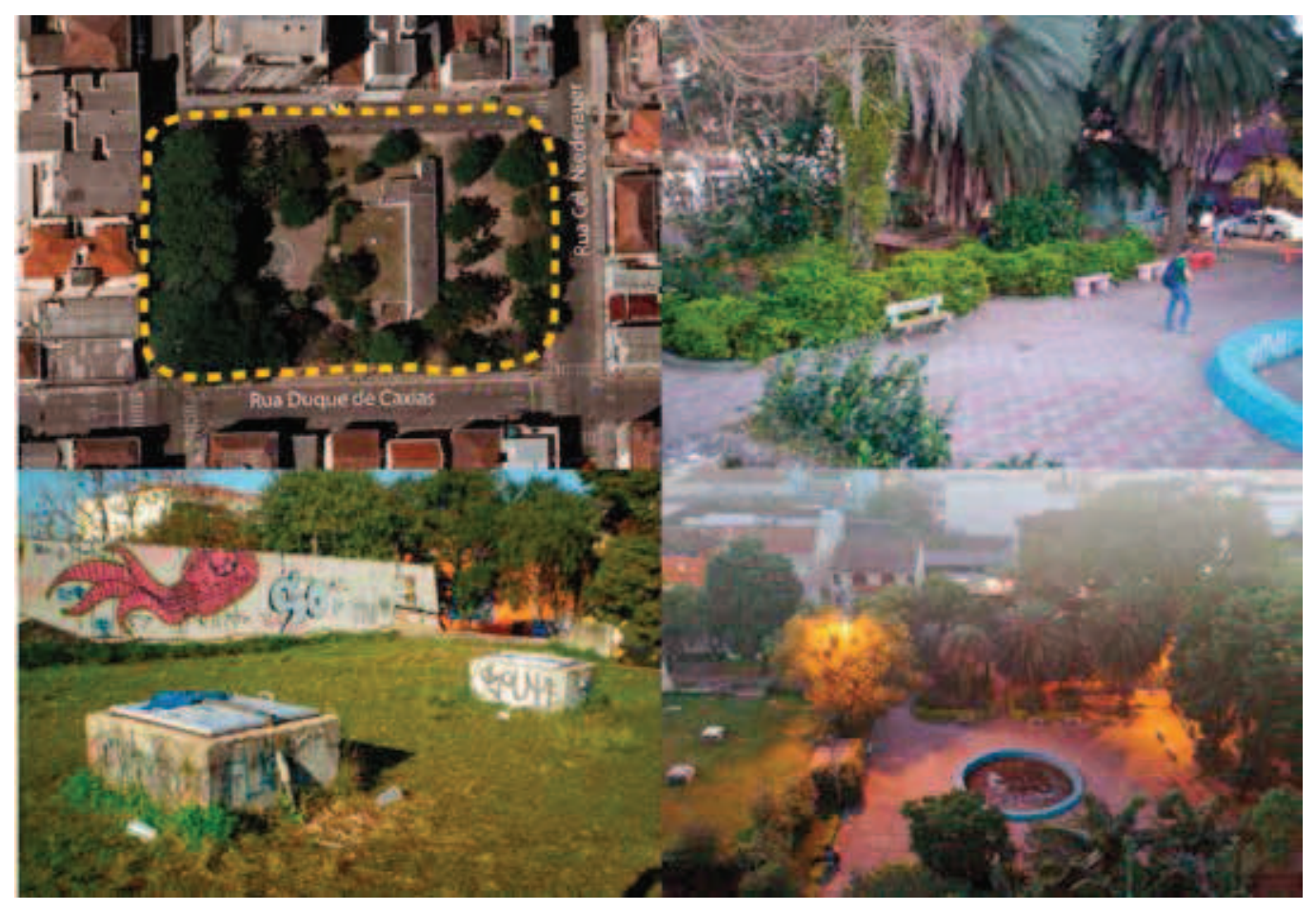

Figura 6 ELIULR - Praça Saturnino de Brito.

Fonte: Arquivo do grupo Quapá-SEL II, núcleo Santa Maria, 2015.

Tabela 6 Ambiência do Parque Jockey Club

\begin{tabular}{l|l}
\hline \multicolumn{1}{c|}{ ELIULR } & \multicolumn{1}{c}{ Parque Jockey Club } \\
\hline Caracterização & $\begin{array}{l}\text { Há cinco anos tornou-se um parque urbano, localizado na região oeste } \\
\text { periférica da cidade de Santa Maria. }\end{array}$ \\
\hline Conflitos & $\begin{array}{l}\text { Projeto inadequado de implantação e composição projetual de paisagismo } \\
\text { que, mesmo subutilizado, mostra-se necessário para a comunidade } \\
\text { residente no entorno. Não existe vegetação, os revestimentos de piso são } \\
\text { inadequados, a execução do projeto está incompleta e configura-se como } \\
\text { uma grande praça seca, comprometendo o uso e a apropriação. }\end{array}$ \\
\hline Potencialidades & $\begin{array}{l}\text { Mantém ambiência e utilização equestre e apresenta um dos maiores visuais } \\
\text { da paisagem em termos de skylines dos morros. }\end{array}$ \\
\hline Usos Públicos & $\begin{array}{l}\text { Cavalgada, área de passagem e circulação, lazer e recreação em } \\
\text { playground e quadra poliesportiva. }\end{array}$ \\
\hline
\end{tabular}

Fonte: Arquivo do grupo Quapá-SEL II, núcleo Santa Maria, 2015. 


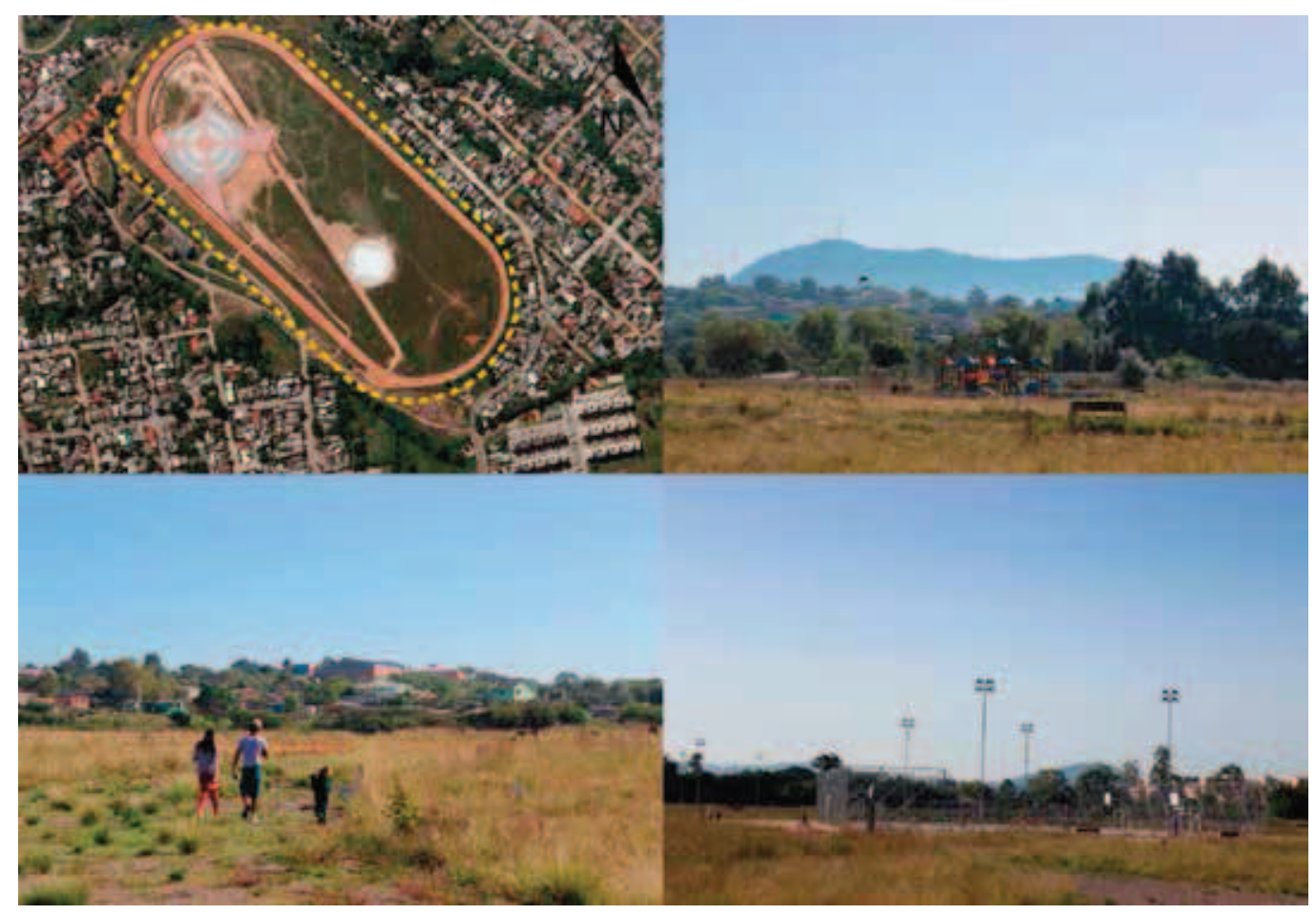

Figura 7 ELIULR - Parque Jockey Club.

Fonte: Arquivo do grupo Quapá-SEL II, núcleo Santa Maria, 2015.

Tabela 7 Ambiência do Parque Nonoai (CACISM)

\begin{tabular}{l|l}
\hline \multicolumn{1}{c|}{ ELIULR } & \multicolumn{1}{c}{ Parque Nonoai (CACISM) } \\
\hline Caracterização & $\begin{array}{l}\text { Através de incentivos privados da CACISM, foi reinaugurado em } 2014 . \\
\text { Apresenta grande importância para a comunidade, relacionada ao lazer e à } \\
\text { prática de esportes. Possui pista de caminhada com } 100 \text { metros de extensão, } \\
\text { playground e aparelhos para atividade física. Mas o estacionamento e o } \\
\text { salão de festas são de uso da CACISM. }\end{array}$ \\
\hline Conflitos & $\begin{array}{l}\text { Por estar sob domínio administrativo da CACISM, apresenta restrições de } \\
\text { horários de uso. A execução do projeto está incompleta e falta arborização } \\
\text { para sombreamento da pista de caminhada e da área com os equipamentos } \\
\text { para exercício físico. Há gradeamento de APP inserida na área do parque, o } \\
\text { que talvez contribua para a situação de local inacessível, sujo e insalubre. }\end{array}$ \\
\hline Potencialidades & $\begin{array}{l}\text { Grande área livre com potencial de tornar-se espaço de convivência e } \\
\text { recreação. Contempla grande parte do bairro e fomenta a prática de } \\
\text { exercício físico. }\end{array}$ \\
\hline Usos Públicos & Exercício físico (caminhar, correr, andar de bicicleta) e convívio social. \\
\hline
\end{tabular}

Fonte: Arquivo do grupo Quapá-SEL II, núcleo Santa Maria, 2015. 


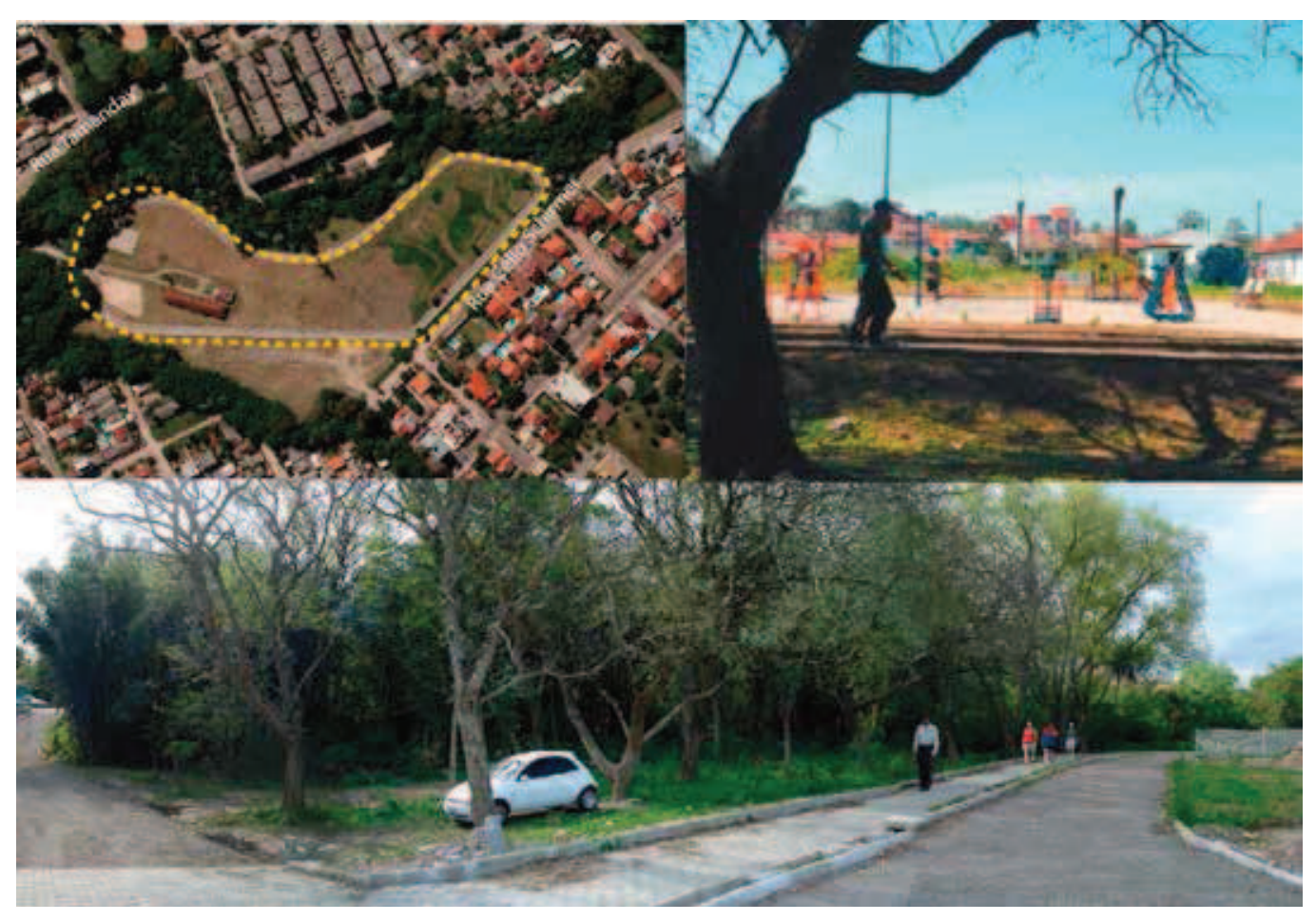

Figura 8 ELIULR - Parque Nonoai.

Fonte: Arquivo do grupo Quapá-SEL II, núcleo Santa Maria, 2015.

Tabela 8 Ambiência da Ciclovia Hélvio Basso

\begin{tabular}{l|l}
\hline \multicolumn{1}{c|}{ ELIUC } & \multicolumn{1}{c}{ Ciclovia da avenida Hélvio Basso } \\
\hline Caracterização & $\begin{array}{l}\text { Canteiro estreito com ciclovia junto à avenida de alto fluxo } \\
\text { motorizado entre a área central e a periferia das regiões sul e } \\
\text { oeste da cidade. Entorno imediato constituído por residências } \\
\text { unifamiliares e usos do setor terciário. }\end{array}$ \\
\hline Conflitos & $\begin{array}{l}\text { Seu uso se torna perigoso na medida em que o tráfego de } \\
\text { automóveis ocorre muito próximo e sem barreira significativa para } \\
\text { a segurança de ciclistas e pedestres. A falta de afastamento da } \\
\text { via de fluxo de alta velocidade faz com que seu uso seja inibido } \\
\text { e inviabilizado para crianças, adolescentes e idosos. Não existe } \\
\text { vegetação, acessibilidade e travessia para os usuários da ciclovia. }\end{array}$ \\
\hline Potencialidades & $\begin{array}{l}\text { Eixo de ligação entre a região sul, oeste e o centro da cidade, } \\
\text { fomenta a prática de exercício físico. }\end{array}$ \\
\hline Usos Públicos & \begin{tabular}{l} 
Caminhar, correr e andar de bicicleta. \\
\hline
\end{tabular}
\end{tabular}

Fonte: Arquivo do grupo Quapá-SEL II, núcleo Santa Maria, 2015. 


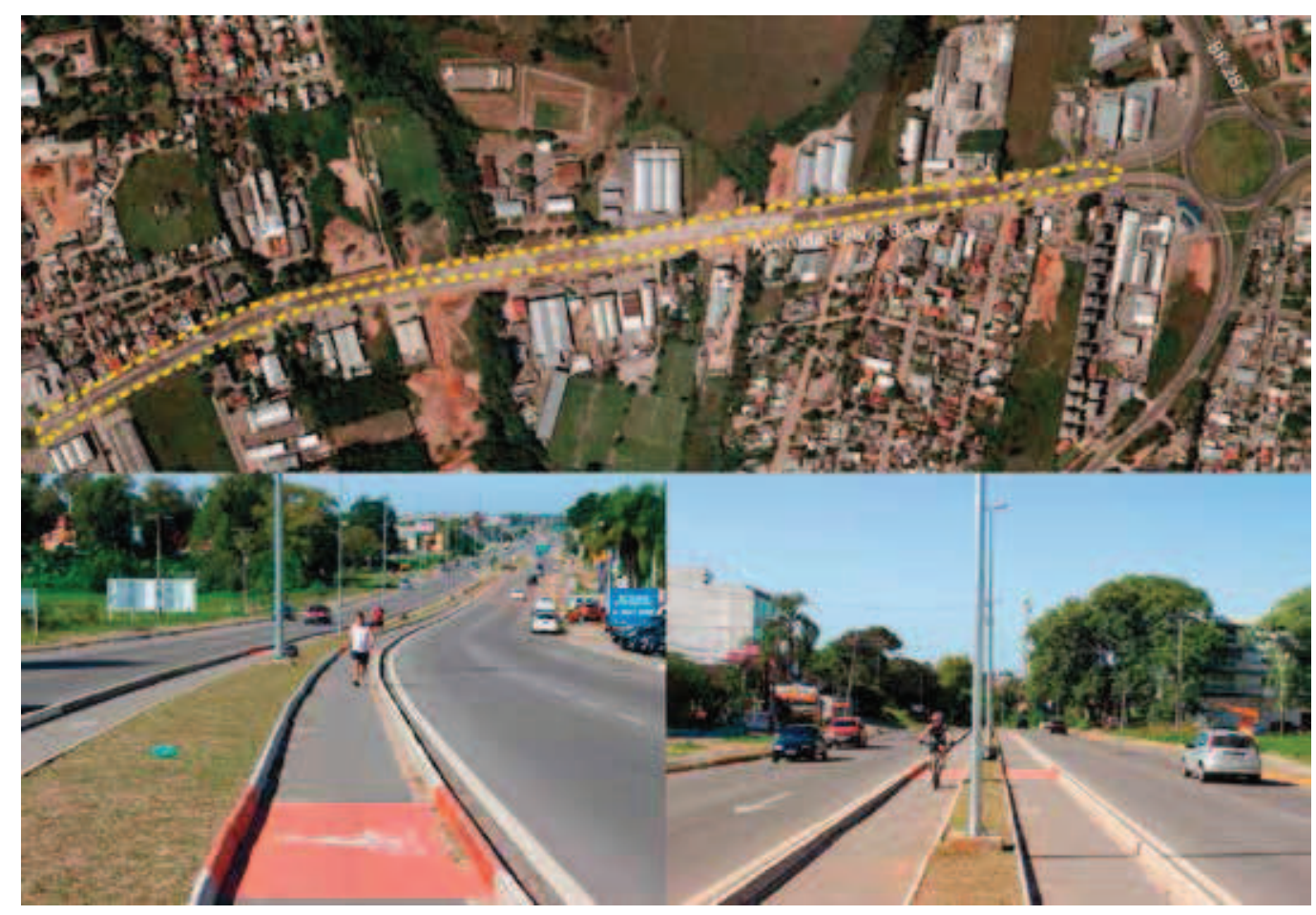

Figura 9 ELIUC - Ciclovia da avenida Hélvio Basso.

Fonte: Arquivo do grupo Quapá-SEL II, núcleo Santa Maria, 2015.

Tabela 9 Pista Multiuso (Campus da UFSM).

\begin{tabular}{l|l}
\hline \multicolumn{1}{c|}{ ELIUC } & \multicolumn{1}{c}{ Pista Multiuso (Campus da UFSM) } \\
\hline Caracterização & $\begin{array}{l}\text { Implementada em 2014, apresentou-se como grande inovação em termos } \\
\text { de uso compartilhado. A pista multiuso caracteriza-se por ser um espaço } \\
\text { alternativo que contempla funções variadas, como andar de bicicleta, skate, } \\
\text { roller, patins, cadeira de rodas, a pé ou contemplação. Seu uso é intenso, } \\
\text { principalmente nos fins de semana em que a universidade recebe público } \\
\text { oriundo de diversas regiões da cidade e região. }\end{array}$ \\
\hline Conflitos & $\begin{array}{l}\text { Seu uso traz conflito no que tange à educação e ao comportamento social } \\
\text { dos usuários em virtude dos usos concomitantes por diferentes meios de } \\
\text { transporte. }\end{array}$ \\
\hline Potencialidades & $\begin{array}{l}\text { Grande potencial de expansão para outras regiões da cidade. Prevê } \\
\text { execução de bicicletários, espaços de convivência e estar no seu entorno. }\end{array}$ \\
\hline Usos Públicos & $\begin{array}{l}\text { Estar, lazer, mobilidade alternativa, recreação (ativa e passiva), } \\
\text { sociabilização, acessibilidade universal. }\end{array}$ \\
\hline
\end{tabular}

Fonte: Arquivo do grupo Quapá-SEL II, núcleo Santa Maria, 2015. 


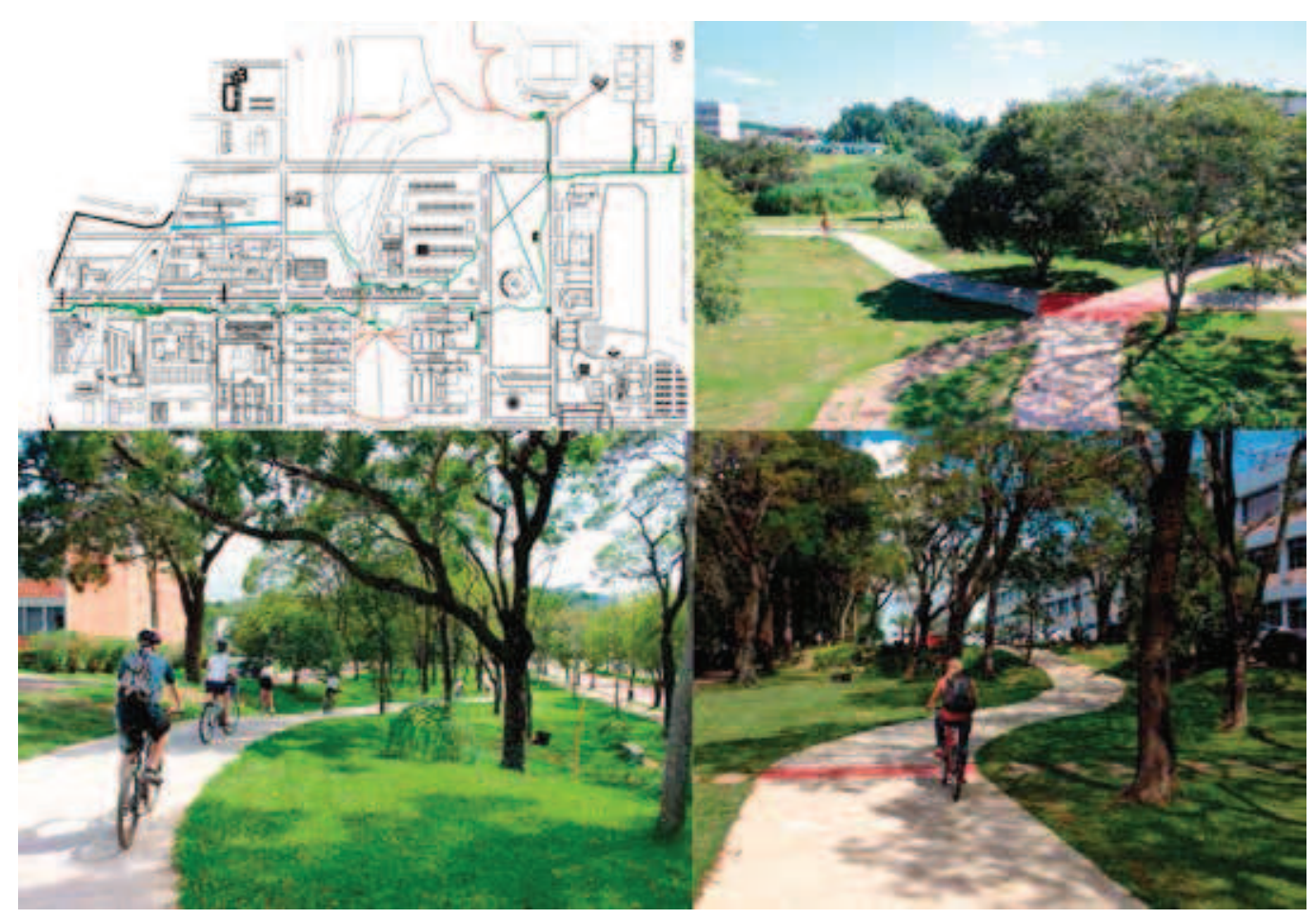

Figura 10 ELIUC - Pista multiuso do Campus da UFSM.

Fonte: Arquivo do grupo Quapá-SEL II, núcleo Santa Maria, 2015. 